\title{
Electrospun nanofiber membranes
}

\author{
Xuefen Wang ${ }^{\mathrm{a} *}$ and Benjamin S. Hsiao ${ }^{\mathrm{b} *}$ \\ ${ }^{a}$ State Key Laboratory for Modification of Chemical Fibers and Polymer Materials, Donghua \\ University, Shanghai, 201620, PR China \\ ${ }^{b}$ Department of Chemistry, Stony Brook University, Stony Brook, NY 11794, USA
}

\footnotetext{
* Corresponding authors:

E-mail address: wangxf@dhu.edu.cn (X. Wang), Benjamin.hsiao@stonybrook.edu (B. Hsiao)
} 


\begin{abstract}
The development of nanofiber technology offers viable means to produce nanofibrous articles, useful for many health, energy and environmental applications. In specific, polymeric nanofibers fabricated by electrospinning can be used as effective membrane materials for environmental remediation due to the light weight, high surface area and interconnected porous structure. In this paper, we review some recent advances in electrospinning for mass production of nanofiber membranes, especially suitable for water purification. These electrospun nanofibers not only can form highly porous membranes with controlled pore size, but also can be functionalized to enhance the separation performance. Various composite membrane formats containing different arrangements of nanofibers have been demonstrated for many sorts of water applications, including microfiltration, ultrafiltration, nanofiltration, reverse osmosis, membrane distillation and adsorption.
\end{abstract}

Keywords: Electrospinning; Nanofiber; Water purification 


\section{Introduction}

\section{Historical background}

The term "nanofiber" is generally referring to a fiber having a diameter less than 1 micron, although the National Science Foundation defines nanofiber as a fiber possessing a diameter of $100 \mathrm{~nm}$ or less. These nanofibers, with very large surface-to-volume ratio, have become an exciting new class of materials useful for many applications, where high porosity is desirable, such as energy storage, health care, environmental engineering, biotechnology, and information technology.

To fabricate submicron polymeric nanofibers, a number of processing techniques, such as electrospinning [1-3], multi-component spinning [4, 5], melt-blowing [4, 5], flash spinning [4], template synthesis $[6,7]$, self-assembly $\left[8,9^{\circ}\right]$, and nanolithography $[10,11]$, have been demonstrated. The effectiveness of these techniques is determined by the overall consideration of applicable polymers, attainable fiber assembly, production rate and production cost. Among these techniques, electrospinning is an extraordinary versatile process that can create nanofibers from a very wide range of polymeric materials. The practicality of electrospinning has been greatly improved with recent advances in mass production scalability, leading to higher production rate and lower cost materials.

The electrospinning technique can be considered as a variant of the electro-spraying process [12]. The first significant patent that described the operation of electrospinning appeared in 1934 [13]. However, this process did not receive much attention until early 1990s, when the Reneker group at the University of Akron notably demonstrated that submicron fibers could be fabricated by electrospinning from a large range of organic polymers [14]. This work greatly revived the research interests of electrospinning by the community. In the past two decades, various synthetic and natural polymers (more than 100 varieties), composites and ceramics have been electrospun from solution, melt, emulsion or suspension into ultra-fine nanofibers with dimensions down to a few nanometers $[2,15,16]$. In addition, these nanofibers could be functionalized by surface modification or by mixing with functional additives such as bioactive molecules, drugs, semiconductors, catalyst nanoparticles or sensing agents. The huge potential in various applications offered by the nanofiber technology based on electrospinning encompasses a multitude of new, 
available polymer nanofibers are [17-19], and their major applications can be summarized schematically in Figure 1. Without question, the major applications of polymer nanofibers will deal with many arising health, environmental and energy challenges. In this review, we will only focus the recent advances of polymer nanofibers for water purification.

\section{New horizon of nanofiber technology for water purification}

Water related problems represent one of the most pressing environmental challenges we face today, and these problems are getting worse with the growing human population. In specific, rapid urbanization and industrialization in the past decades have made people acutely aware of many emerging water problems that did not exist before. It has been reported that about $40 \%$ of the Earth's population (over 2.5 billion) live in water-stressed areas and about 1.2 billion people live without clean drinking water. It is estimated that the number of people facing freshwater shortage will reach 3.5 billion by 2025 . One major class of inorganic pollutants having great physiological impacts is heavy metals (i.e., $\mathrm{Hg}, \mathrm{Pb}, \mathrm{Cu}$ and $\mathrm{Cd}$ ). Industries such as plating, ceramics, glass, mining and battery manufacturing can be main sources of heavy metal contamination to the local water supply. For organic pollutants, the level of concentration that would cause health hazards can be even lower than those of heavy metals, thus becoming even more pressing water issues.

Consequently, there is a dire need to develop more efficient and more cost-effective filtration and separation technologies to deal with many emerging water challenges than the existing methods. In conventional methods, both filtration and adsorption processes are considered as effective means to remove unwanted species in contaminated water, or prevent harmful contaminants from getting into the environment and the human body. It has been demonstrated that polymer nanofibers offer a suitable platform that can combine both functions of filtration and adsorption together. This is because nanofibrous scaffold has low basis weight and high porosity (e.g., over $80 \%$ ), thus offering high permeability, as well as small pore size (at the submicron range), making them suitable for microfiltration applications [20-22]. Their very high surface-to-volume ratio and the ease of incorporating special functionality of polymer nanofibers also make them an excellent adsorption medium for removal of contaminants [22-24]. 
Electrospinning turns out to be a viable technique that can fabricate continuous polymer nanofibers from a wide range of polymers $[1,2]$. The resulting scaffold has a membrane structure with high porosity and interconnected pores that are suitable for microfiltration application. The attainable pore size in such a scaffold, which can be controlled by the fiber diameter and the scaffold thickness, is usually in the range of sub-microns. In the following sections, recent advances of electrospinning technology for fabrication of water filtration membranes, and the applications of electrospun scaffolds as filtration (microfiltration and ultrafiltration), adsorption or membrane distillation media are reviewed. Without questions, nonwoven nanofibrous articles have become an extremely promising and versatile water purification platform, where more innovative, robust and cost-effective nanofiber technologies will further expand the potential of this platform.

\section{Fabrication of nanofibers by electrospinning}

\section{Principle of electrospinning}

Electrospinning is a polymer solution spinning process driven by electrical force. A typical electrospinning process involves the application of an electrical field, induced by a high-voltage power supply, between the polymer solution or melt in a spinneret and a collector (a counter or grounded metal electrode such as a plate or a rotating drum) separated at a suitable distance (Figure 2). Under a sufficiently high field, electrical force would overcome the surface tension of the polymer solution, deforming the pendent drop at the tip of the spinneret into a "Taylor cone", and resulting in the ejection of a thin jet [1]. The charged jet undergoes a stable stretching firstly, then it starts bending and whipping randomly that leads to further stretching due to the combined effects of solvent evaporation and charge repulsion. This unstable stretching can result in a very large spin-draw ratio, where the terminal jet speed can reach a fraction of the sound speed. As a result, the solidified fibers on the collector can be in sub-micron diameter and has a randomly oriented non-woven structure.

The diameter, shape and surface morphology of the fibers and the texture of the scaffold produced by electrospinning depend on a number of parameters [25-27]. These parameters include (a) the intrinsic properties of the polymer solution, such as molecular weight and molecular weight distribution of the polymer, the conformation of polymer chains, viscosity (depending on the concentration and intermolecular force), surface tension, electrical conductivity, solvent va- 
por pressure, and $\mathrm{pH}$ value, (b) the operational conditions, such as the strength of the electrical field, electrode geometry and separation gap distance (if with multiple electrodes), distance between the spinneret and collector, rotating speed of the collector, feeding rate of the polymer solution, and (c) the surrounding conditions, such as the humidity and temperature, as well as the air speed in the electrospinning chamber (i.e., the solvent evaporation rate). For example, Casper et al. [27] investigated the effect of humidity on the resulting electrospun nanofibers, whereas porous electrospun fibers could be obtained when electrospinning was carried out under elevated humidity. Thompson et al. [25] demonstrated that the effect of humidity on the fiber structure is strongly coupled to other processing parameters. As the electrospinning is a rapid solidification process, occurring at the millisecond scale, nucleation and growth of the phase separation would therefore be different from those in bulk materials. Thus, different morphology of the resulting fiber (e.g., surface and inner structures, including beaded, porous, branched, tubular, zonal structures, and so on) could be obtained under different operating conditions [19, 28].

\section{Mass production of nanofibers by electrospinning}

It is well-known that the single-jet electrospinning process yields a very low production rate. For example, an electrospun nanofibrous mat with $1 \mathrm{~g}$ of weight may take several hours to fabricate using a single spinneret. The multiple-jet electrospinning process involving many spinnerets is a practical way to deal with this problem [29-32]. In a laboratory setting, one straightforward way to implement multiple-jets is by using an array of syringes as spinnerets [29]. In this operation, the polymer solution was distributed to multiple syringes using a programmable syringe pump to maintain the minimum pressure drop. The same design can be scaled up in an industrial setting.

In another demonstration, the Chase group in Akron University [30 $0^{\circ}$ used a cylindrical porous tube as a source to provide multiple-jet electrospinning, where many jets could be formed on the porous surface of the tube. The production rate of this system could be scaled up by increasing the tube length and the number of holes. Our group at Stony Brook also demonstrated a multiplejet electrospinning technique assisted by a hot air stream, termed blowing-assisted electrospinning or electroblowing technique [33]. The air flow added an initial mechanical pulling force to the jet stream as well as further control of the solvent evaporation rate, thereby also affecting the resulting fiber diameter [34, 35]. Recently, Chen's group from Donghua University also de- 
signed a multiple-jet electrospinning apparatus using a multiple-spinneret distribution plate (i.e., an array of spinnerets connected on a multi-hole distribution plate) similar with that in conventional textile spinning process $[31,32]$. Their design further improves the electrospinning production rate for practical industrial processing.

A completely different approach to mass produce nanofibers by electrospinning was developed by the Elmarco Company, which termed the technology as "Nanospider" electrospinning. This technology is a needle-free, liquid surface electrospinning process. Multiple-jets could be ejected from the surface of polymer solution with the assistance of a metal electrode, where the production rate of the spinning unit could reach $20000 \mathrm{~m}^{2} / \mathrm{d}$.

\section{Nanofiber membranes for water filtration}

For water filtration, most porous polymeric membranes, manufactured by the conventional phase inversion method, have their intrinsic limitations, such as low flux (thus high energy cost) and high-fouling tendency due to the asymmetric void structure formation of pores across the membrane thickness and the corresponding pore size distribution [103]. Nanofiber-based membranes are good alternatives that can surpass conventional membranes. This is because nanofiber membranes have relatively high porosity (typically around $80 \%$ ), fully interconnected open pore structures and controllable pore size distribution from microns to sub- microns, thus providing high permeability for water filtration. Some examples of nanofiber-based membranes for energy efficient pressure-driven liquid separations involve microfiltration, membrane distillation, ultra/nanofiltration and pervaporation, which are discussed next.

\section{Nanofiber filters}

\section{Nanofiber membranes for microfiltration}

Microfiltration that can remove particulates (microns to sub-microns) in the liquid environment is a pressure-driven, sieving-based filtration process, which plays an important part in the potable water purification and wastewater treatment that requires the separation of suspended microparticles and bacteria. The versatile electrospinning technique has provided an ideal pathway to construct nanofiber-based microfiltration membrane with controllable pore size and pore size 
distribution, which has become a superior alternative to replace the traditional microfiltration membrane [36].

For example, Gopal and Aussawasathien demonstrated that they were able to remove polystyrene (PS) particles (diameter from 0.1-10 $\mu \mathrm{m}$ ) in a liquid environment using electrospun nanofiber membranes made of polyvinylidene fluoride (PVDF) [37], polysulfone (PSF) [38] and nylon6 [39]. The average diameters of the electrospun PVDF, PSF and nylon-6 nanofibers were 380 $\mathrm{nm}, 470 \mathrm{~nm}$ and $110 \mathrm{~nm}$, respectively, and the pore sizes of the corresponding nanofiber membranes were in the range of 4.0-10.6 $\mu \mathrm{m}, 1.2-4.6 \mu \mathrm{m}$ and 6.0-7.7 $\mu \mathrm{m}$, respectively. It was found that when PS particles with a mean diameter of $10 \mu \mathrm{m}$ ( $>$ the membrane pore size) were used, the membrane worked as a screen filter and showed excellent rejection ratio ( $>95 \%)$. The membrane also exhibited no permanent fouling tendency (Figure 3A), i.e., the flux of the used membranes could be fully recovered by reverse washing with water. However, the membrane could be irreversibly fouled when PS particles with a mean diameter of $1 \mu \mathrm{m}$ were used (Figure 3B). In the above two scenarios, a dense cake-layer was formed on top of the membrane during filtration, where a sharp decrease in flux and a rapid increase in rejection were seen. When particles with an average size of $0.1 \mu \mathrm{m}$ were used, the membrane behaved as a depth filter. For example, a large amount of small PS particles were adsorbed on the nanofiber surface at the distance about $1 \mu \mathrm{m}$ below the membrane surface (Figure 3C).

Recently, Veleirinho and co-workers $\left[40^{\circ}\right]$ investigated the application of electrospun polyethylene terephthalate (PET) nanofiber membranes for apple juice clarification. This membrane system showed a higher flux performance, i.e., much faster, simpler and more cost-effective than the conventional system. Liu and co-workers also demonstrated a high-flux microfiltration filter, made of electrospun polyvinyl alcohol (PVA) nanofibrous scaffold cross-linked with glutaraldehyde in acetone. This water-resistant PVA nanofiber membrane showed 3-7 times higher pure water flux than the Millipore GSWP membrane with $0.22 \mu \mathrm{m}$ pore size and could reject higher than $98 \%$ of $0.2-\mu \mathrm{m}$-sized polycarboxylate microsphere particles [41].

In general, when an electrospun mat containing non-woven nanofibers of $100 \mathrm{~nm}$ diameters is used as a screen filter, it can efficiently separate particulates with sizes larger than $300 \mathrm{~nm}$ [42]. It appears that at the optimal membrane thickness (i.e., highest flux and highest rejection rate), 
there is a linear relationship between the pore size and the fiber diameter, when the membrane has a non-woven structure and high porosity (e.g., around 70\%). Hsiao and co-workers have confirmed this relationship and discovered that the mean pore size was about $3 \pm 1$ times the mean fiber diameter, and the maximum pore size was about $10 \pm 2$ times the mean fiber diameter [43]. Thus, the membrane pore sizes can be adjusted by controlling the electrospinning parameters, allowing the design of a suitable system to meet different microfiltration applications.

Purification of potable water for drinking is indispensable in our daily life. Suitable technologies must be able to separate undesired components, such as sand, organic suspended particles, parasite, giardia lamblia, cryptosporidium, bacteria, algae, viruses and fungi, etc., from the water supply. Generally, the sizes of most aquatic bacteria are larger than $0.2 \mu \mathrm{m}$, where electrospun nanofiber membranes with smaller pore dimensions can be an ideal microfiltration filter platform for water purification. Chu and Hsiao's group from Stony Brook has conducted a series of studies for this application. For example, they demonstrated that a microfiltration membrane with maximum pore size of $0.62 \pm 0.03 \mu \mathrm{m}$ and mean pore size of $0.22 \pm 0.01 \mu \mathrm{m}$, which was fabricated by electrospinning of polyacrylonitrile (PAN) nanofibers on the surface of polyethylene terephthalate (PET) non-woven substrate, performed significantly better (i.e., higher flux while maintaining a very high rejection ratio $(99.9999 \%)$ of bacteria) than the commercial microfiltra-

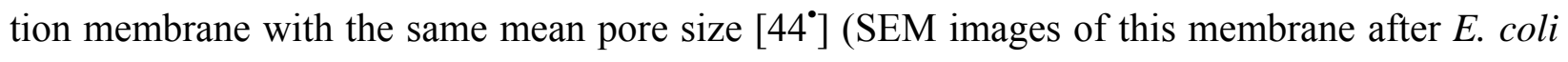
filtration are shown in Figure 4). Furthermore, functionalized electrospun PAN/PET microfiltration membranes were also developed by impregnating ultra-fine cellulose nanowhiskers (diameter about $5 \mathrm{~nm}$ ) into the PAN nanofibrous scaffold [45-47] or by polymerizing dual-vinyl and trivinyl monomers on the surface of PAN nanofibers [48], where this system could also be used as an absorbent to effectively remove additional viruses and toxic metal ions.

\section{Nanofiber membranes for oil/water separation}

Due to the rapid increase in the production of industrial oily wastewater, accompanied by the frequent oil spill accidents (e.g., the catastrophic Deepwater Horizon oil spill in the Gulf of Mexico), it is of vital importance to develop new technologies that can separate oil and water in a more efficient manner for many water purification operations. Conventional techniques such as skimming, ultrasonic separation, air flotation, gravity processing, membrane filtration and coagu- 
lation-flocculation often incur some shortcomings, such as low separation efficiency, high energy-cost, secondary pollution and complex separation devices. Clearly, the discovery of environmentally friendly and cost-effective functional materials that can lead to more energy-efficient oil/water separation technologies is urgently desired.

It appears that electrospun articles can provide a vital platform to meet some of the challenges. For example, in consideration of the separation of oil and water using gravity or other low pressure sources, a microfiltration filter having a combined superhydrophobic layer and superhydrophilic electrospun nanofibrous scaffold structure was designed and demonstrated [49-54]. Tang and co-workers [54] reported a unique membrane system for gravity-driven oil and water separation, using a facile combination of electrospun poly(m-phenylene isophthalamide) (PMIA) nanofibrous scaffold (superhydrophilic) and an in-situ polymerized fluorinated polybenzoxazine (FPBZ) functional layer containing $\mathrm{SiO}_{2}$ nanoparticles (superhydrophobic). The membrane system exhibited excellent separation capability and also showed good repellency to hot water $\left(80^{\circ} \mathrm{C}\right)$. However, as water has a higher density than most oils, a superhydrophilic and underwater superoleophobic membrane system is more desired. For this purpose, Ahmed and co-workers [55] demonstrated a novel "water-removing" membrane system by electrospinning polyvinylidene fluoride-co-hexafluoropropylene (PVDF-HFP) nanofibrous scaffolds, which were subsequently modified with cellulose.

However, the separation of emulsified oil and water mixtures, especially surfactant stabilized emulsions with a dispersed droplet size below $20 \mu \mathrm{m}$, has turned up to be challenging using the format of microfiltration membrane. To deal with this challenge, Ding and co-workers successfully demonstrated a series of superwetting hierarchical electrospun nanofiber membranes that could separate water-in-oil [56] as well as oil-in-water [57-58] micro-emulsions (with a micron droplet size). In specific, a flexible, thermally stable and hierarchical porous silica-based electrospun nanofiber membrane system having superhydrophilicity and underwater superoleophobicity was demonstrated using a facile combination of electrospun silica nanofibers and in situ polymerized polybenzoxazine (PBZ-CHO, from an aldehyde benzoxazine monomer) functional layer containing $\mathrm{SiO}_{2}$ nanoparticles. This system can effectively separate oil-in-water microemulsions solely driven by gravity, with an extremely high flux of $2237 \mathrm{~L} / \mathrm{m}^{2} \mathrm{~h}$ (as shown in Figure 5) $\left[58^{\circ}\right]$. However, in typical industrial oily wastewater treatments, the dispersed droplet sizes 
of oil/water emulsions are often smaller, some in the nanoscale range. To overcome this challenge, it is necessary to use a hydrophilic ultrafiltration membrane system to separate oil and water in nano-emulsions, where nanofiber membrane was also found to provide great application potential which will be discussed later.

\section{Nanofiber membranes for membrane distillation}

Membrane distillation (MD) is a thermally-driven non-isothermal separation process, in which only vapor molecules can transfer through a highly hydrophobic microporous membrane. The driving force in the MD process is the vapor pressure difference induced by the temperature difference between the feed and permeate flows [59]. Since the first report by Feng and co-workers using PVDF nanofiber membranes for air-gap MD operations to produce drinking water $(\mathrm{NaCl}$ concentration $<280 \mathrm{ppm}$ ) from saline water containing $6 \mathrm{wt} \% \mathrm{NaCl}$ solution [60], various approaches have been investigated to fabricate PVDF nanofiber membranes with improve MD performance $\left[61^{\circ}, 62,63,64^{\circ}\right]$. For example, Essalhi and co-workers [61'] studied the effect of concentration on the characteristics of electrospun PVDF membranes and the corresponding DCMD desalination performance, where the optimum nanofiber membrane exhibited a DCMD permeate flux of $12.2 \times 10^{-3} \mathrm{~kg} / \mathrm{m}^{2} \mathrm{~s}$ for distilled water and $10.8 \times 10^{-3} \mathrm{~kg} / \mathrm{m}^{2} \mathrm{~s}$ for $30 \mathrm{~g} / \mathrm{L}$ (or $3 \mathrm{wt} \%$ ) $\mathrm{NaCl}$ feed solution, respectively (the feed temperature was $80{ }^{\circ} \mathrm{C}$ and the permeate temperature was 20 ${ }^{\circ} \mathrm{C}$ ), where the $\mathrm{NaCl}$ rejection factor was higher than $99.99 \%$. Liao and co-workers [62] also investigated the effect of polymer compositions, electrospinning parameters and heat-press posttreatment on the electrospun PVDF membranes, where the post-treated nanofiber membranes were able to produce a permeation flux of about $21 \mathrm{~kg} / \mathrm{m}^{2} \mathrm{~h}\left(\right.$ or $5.8 \times 10^{-3} \mathrm{~kg} / \mathrm{m}^{2} \mathrm{~s}$ ) throughout the testing period of $15 \mathrm{~h}$ for $3.5 \mathrm{wt} \% \mathrm{NaCl}$ feed solution (the feed temperature was $50{ }^{\circ} \mathrm{C}$ and the permeate temperature was $20^{\circ} \mathrm{C}$ ). In addition, systematic studies of the membrane thickness effect on the DCMD performance were also carried out by Essalhi et al. [63 $]$ and Wu et al [64 $]$.

To achieve higher efficiency and more stable DCMD performance for desalination, various modification schemes to improve PVDF nanofiber membranes were presented [65-69]. The modification schemes included hot-pressed polyvinylidene fluoride-co-hexafluoropropylene (PVDFHFP) nanofiber membranes [65], nanocrystalline cellulose reinforced PVDF-HFP nanofiber membranes [66], nanofiber membranes based on PVDF blended with clay nanoparticles [67], 
nanofiber membranes based on PVDF-PTFE blends [68], and nanofiber membranes based on silver coated PVDF/poly-dopamine electrospun scaffolds with thiol surface modification [69]. Recently, Liao and co-workers $\left[70^{\circ}, 71^{\circ}\right]$ demonstrated a self-cleaning composite nanofiber membrane system consisting of a superhydrophobic silica-PVDF composite selective skin on the PVDF nanofibrous scaffold inspired by the lotus leaf. The PVDF nanofiber membranes with the "lotus effect" exhibited a stable permeate flux of $18.9 \mathrm{~kg} / \mathrm{m}^{2} \mathrm{~h}$ ( or $5.8 \times 10^{-3} \mathrm{~kg} / \mathrm{m}^{2} \mathrm{~s}$ ) over $50 \mathrm{~h}$ of testing time using a $3.5 \mathrm{wt} \% \mathrm{NaCl}$ feed solution (the feed temperature was $50{ }^{\circ} \mathrm{C}$ and the permeate temperature was $20^{\circ} \mathrm{C}$ ). This result was superior to conventional PVDF flat-sheet membranes tested under the same or similar conditions.

Some researchers also reported other electrospun superhydrophobic nanofiber membranes for MD operation, such as electrospun aromatic fluorinated polyoxadiazoles and polytriazoles membranes [72], electrospun PTFE nanofiber membrane [73] and dual-biomimetic superhydrophobic electrospun PS micro/nano-fibrous membranes [74], which all showed superior performance in purifying the $\mathrm{NaCl}$ feed solutions over conventional MD membranes. Thus, electrospun nanofiber membranes with superhydrophobic properties and suitable pore sizes are ideally suited for MD applications for desalination of seawater or brackish water.

\section{Thin-film nanofibrous composite (TFNC) membranes}

Thin film composite (TFC) membranes have become the most widely used membrane system in filtration, including ultrafiltration, nanofiltration and reverse osmosis, to separate undesired components of small sizes in water. Generally, TFC membranes offer the characteristics of good rejection ratio, decent permeability, good mechanical properties and reasonably low cost. Such a membrane system consists of multi-layered structure: a non-woven substrate that gives the mechanical support, an asymmetric porous polymer layer that can offer either filtration function (i.e., ultrafiltration, UF) or support function, and a very thin barrier layer having very small pore size in nanoscale (i.e., nanofiltration, NF, and reverse osmosis, RO). Recent studies indicated that both the porous polymer layer and top barrier layer could be replaced by nanofibrous scaffolds with fiber diameters ranging from hundreds of nanometers to a few nanometers. This whole fibrous membrane structure is termed thin-film nanofibrous composite (TFNC) membrane format. Nanofibrous scaffolds offer the unique properties of high porosity and interconnected 
pore structures, thus enabling TFNC membranes to have higher permeability (or low energy consumption cost) than conventional TFC membranes.

\section{Ultrafiltration TFNC membranes}

In recent years, the large-scale oil and gas productions can generate a very large amount of produced water, contaminated by organic chemicals, emulsified oils, etc., unsafe for human consumption or even agricultural use. Therefore, the efficient removal of oil emulsions in water has a topic of great research interest and industrial importance. In many operations, the size of the oil emulsions can be less than $50 \mathrm{~nm}$, which are very difficult to be removed by previous mentioned nanofiber membranes with microfiltration pore sizes. This is because the pore sizes of most nanofiber membranes, fabricated by electrospun nanofibers, cannot be easily reduced to less than $100 \mathrm{~nm}$, resulting in very low rejection. To overcome such a problem, one simple method is to apply the concept of TFC membrane to the nanofibrous scaffold, which forms the three-layered composite structure in TFNC membrane $\left[75,76,7^{\circ}\right]$, as shown in Figure 6 . The first demonstrated TFNC membrane system with UF/NF performance that can successfully remove oil emulsions in water consisted of: a 'non-porous' hydrophilic top barrier layer (to improve the hydrophobic fouling tendency), a mid-layer electrospun nanofibrous scaffold, and a conventional non-woven micro-fibrous support.

For example, Chu and Hsiao group [76, $77^{\circ}$ first reported a high-flux TFNC-based UF membrane system containing electrospun poly(vinyl alcohol) (PVA) nanofibrous scaffold as the midlayer, and PVA hydrogel coating or hydrophilic Pebax ${ }^{\circledR}$ coating as the hydrophilic barrier layer. Results indicated that these unique hydrophilic TFNC membranes exhibited a very high flux (several times higher than conventional TFC-based UF membranes) and comparable high rejection ratio for oil and water emulsion separation. Interestingly, the incorporation of nanofillers (such as surface-oxidized multi-walled carbon nanotubes) into the hydrophilic coating layer further improved the water transport in the barrier layer and markedly increase the permeate flux $\left[77^{\circ}\right]$.

In 2011, Chu and Hsiao group [78“, $79^{\circ}, 80$, and $81^{\circ}$ ] demonstrated a unique TFNC membrane system, using ultra-fine polysaccharide nanofibers (diameters 5-10 nm) to fabricate the barrier layer (Figure 7), which also exhibited excellent high-flux and low-pressure UF performance. 
This system represents a whole fibrous membrane system, containing three layers of non-woven fibers with different diameters (ranging from microns to a few nanometers). For example, a TFNC membrane containing the barrier layer made of ultra-fine cellulose nanofibers (diameter around $5 \mathrm{~nm}$ ), mid-layer made of electrospun PAN nanofibers (diameter around $150 \mathrm{~nm}$ ), and PET non-woven substrate (diameter around $20 \mu \mathrm{m}$ ) exhibited a 10-fold higher permeation flux than a commercial UF membrane for separation of oil emulsions and water, which retaining the same rejection ratio (above 99.5\%) [78*0.

The preparation of an appropriate thin barrier layer on the highly porous electrospun non-woven nanofibrous scaffold often faces a series of challenges. For example, using the conventional casting method, penetration of the coating solution into the nanofibrous scaffold is unavoidable, which would result in a much thicker barrier layer. Various methods, such as adjusting the viscosity of the cast solution through gelation $\left[76,77^{\circ}\right]$, soaking the nanofibrous scaffold with coagulant of the cast solution $[75,82,83]$ and photo-crosslinking of UV-reactive coating solution (e.g., photo-cross-linkable PVA) [84], have been demonstrated to minimize the penetration of the cast solution and optimize the barrier thickness. Recently, Wang and coworkers demonstrated a unique technique to prepare an ultra-thin barrier layer on the nanofibrous scaffold $\left[85^{\circ}, 86^{\circ}, 87\right]$. In their approach, a two-layered electrospun nanofibrous mat, containing a thin hydrophilic top layer and a nanofibrous support layer, was manufactured via electrospinning. The top electrospun layer was subsequently melted using solvent vapor or solvent solution to form a thin barrier layer without the fibrous structure. In one of their studies, an electrosprayed PVA top layer was swollen in water/acetone mixture to form a film like barrier layer on the electrospun PAN support layer (Figure 8). The resultant TFNC membrane, containing cross-linked PVA barrier layer, possessed very high flux $\left(347.8 \mathrm{~L} / \mathrm{m}^{2} \mathrm{~h}\right)$ and high rejection ratio $(99.6 \%)$ at low pressure $(0.2 \mathrm{MPa})$

for separation of oil emulsion and water $\left[86^{\circ}\right]$. The system was able to maintain a much higher flux value than typical commercial UF membrane with no loss of oil rejection capability under a long cross-flow ultrafiltration operation. This method overcomes the typical challenge of easy penetration of the coating solution into the porous substrate and thus offers great potential in fabrication of TFNC membranes.

\section{Nanofiltration and reverse osmosis TFNC membranes}


To remove smaller size contaminants, such as salt ions or chemicals, membrane technologies based on nanofiltration (NF) and reverse osmosis (RO) have become increasingly important. For example, the use of electrospun nanofiber membranes to purify low salt content water by NF has recently been investigated [88]. In this study, the authors argue that TFNC membranes mainly have two advantages, namely the ability to control the top barrier layer thickness as well as selection of suitable nanofibrous substrate. Thus, the optimization of these two layers with respect to structure and stability will lead to better filtration performance. We believe, aside from the above viewpoint, the format of TFNC membranes offers two unique features that can produce highly permeable or energy efficient nanocomposite membranes for NF or RO operations. These features include: (1) the replacement of the conventional flux-limited porous substrate with a higher flux electrospun nanofibrous scaffold, and (2) the creation of a nanocomposite barrier layer, containing interconnected "directed water channels" formed between the imbedded nanofibers and cross-linked polymer matrix. The conventional barrier layer for reverse osmosis consists of tightly cross-linked structures with non-directed or torturous water channels, often resulting in low flux performance. In (2), the introduction of directed water channels can lead to a significant increase in flux and mechanical strength during NF/RO operations, without loss of selectivity. However, this research is still at its infantry, where more research is necessary to allow us better optimize the relationships between water channel structure and filtration performance.

The filtration performance of TFNC membranes is directly dependent on the barrier layer thickness. The interfacial polymerization technique is a common and effective method to prepare the thin barrier layer by employing two immiscible phases containing reactive monomers, e.g., aqueous amine phase and organic acyl halide phase. When these two phases meet, a rapid condensation polymerization would occur. Yoon et al. [89] demonstrated that electrospun nanofiber membranes could be used as scaffolds to support the interfacially polymerized polyamide barrier layer. In their study, an electrospun PAN nanofibrous scaffold was used as the mid-layer support and the barrier layer was produced by interfacial polymerization of polyamides containing different ratios of piperazine and bipiperidine. Their results indicated that the membranes exhibited about 2.4 times higher permeate flux than conventional composite membranes having the same chemical compositions, while maintaining the same rejection ratio $(\sim 98 \%)$ to divalent salts $\left(\mathrm{MgSO}_{4}\right)$. Yung et al. further used ionic liquids as additives in interfacial polymerization to improve the permeation flux of the barrier layer in TFNC NF membranes [90]. The existence of 
non-reactive ionic liquid during polymerization clearly affected the structure of the barrier layer and corresponding nanofiltration properties. It was found that the presence of small ion liquid molecules reduced the permeation flux but increased the salt rejection ratio, while the presence of larger ion liquid molecules could increase the permeation flux but only slightly reduced the salt rejection ratio. The demonstrated TFNC membrane exhibited 2 times higher permeation flux than that of the commercial NF-90 membrane with comparable salt rejection ratio, and comparable permeation flux and salt rejection performance as those of the commercial NF-270 membrane.

The good wetting ability of the porous support is known to play a pivotal role in the formation of a thin and defect-free barrier layer. Normally, the porous support was first wetted by an aqueous amine solution that could rapidly react with the subsequently cast organic solution. When a hydrophobic material is used as the porous support for interfacial polymerization, the support is difficult to be totally wetted by the aqueous solution and form a uniform liquid amine layer. To overcome this problem, the hydrophobic electrospun nanofibrous support could be modified by oxidant for a short period of time to improve the hydrophilicity [91, 92]. Using an unmodified and hydrophobic electrospun PVDF nanofibrous support, Zhang and coworkers reported a high performance composite ultrafiltration TFNC membrane system fabricated by post interfacial polymerization [93]. The pure water flux of this membrane was $67 \mathrm{~L} / \mathrm{m}^{2} \mathrm{~h}$, and the BSA rejection was $98 \%$ under the pressure of $0.3 \mathrm{MPa}$.

Hsiao and Chu's group $[94,95]$ prepared a series of TFNC NF membranes fabricated by interfacial polymerization of polyamide around the ultra-fine cellulose nanofibers layer (Figure 9). Two interfacial polymerization pathways termed IP (the organic phase on top of the aqueous phase) and IP-R (the aqueous phase on top of the organic phase), regarding the arrangement of the composite substrate into aqueous or organic phases, were investigated [94]. It was found that interfacial polymerization with the aqueous phase above the organic phase (IP-R) yielded better filtration performance than IP based membranes, i.e., IP-R based membranes exhibited a higher $\mathrm{MgCl}_{2}$ rejection than IP based membranes due to a dense barrier layer formation on top of the nanofibrous substrate via the IP-R route. With the optimized organic solution delivery using a slot die coating machine, the best performing membrane exhibited a permeation flux of 71.7 $\mathrm{L} / \mathrm{m}^{2} \mathrm{~h}$ and a rejection ratio of $98.5 \%$ against $\mathrm{MgSO}_{4}$, which were better (i.e., about 2 times high- 
er flux) than those of the commercial NF 270 membrane having similar barrier layer chemical compositions [95].

\section{TFNC membranes for pervaporation}

Recently, the pervaporation process has received a great deal of attention due to its higher separation efficiency (e.g., separation of alcohol and water) and low energy cost compared to the conventional distillation process. Pervaporation is a membrane separation technique that combines permeation and vaporization. During the process, the feed is a liquid phase and the permeation is a vapor phase. Generally, the pervaporation process requires the use of non-porous, dense polymer membranes. However, recent studies indicated that the reduced mass transfer resistance and increased mass transfer efficiency could be achieved by using composite nanofiber membranes, resulting in higher flux. For example, Yeh and co-workers demonstrated the application of a TFNC membrane system for pervaporation to separate water and ethanol [96]. This membrane system consisted of a cross-linked PVA hydrophilic barrier layer, a cellulose nanofibrous buffer layer, an electrospinning nanofibrous support layer with high porosity and fully interconnected pore structure, and a PET non-woven substrate. The resulting membrane possessed excellent performance in the water/ethanol pervaporation measurement, where the separation factor could reach 80.8 with a flux of $765 \mathrm{~kg} / \mathrm{m}^{2} \mathrm{~h}$ that was significantly higher than any commercial pervaporation membranes. They also demonstrated that the cross-linked PVA layer could be replaced by a thin layer of graphene oxide (fabricated by spin coating or vacuum filtration method), creating a new TFNC membrane system for ethanol dehydration [97]. This membrane system exhibited high water permeability (flux of $2.2 \mathrm{~kg} \mathrm{~m}^{-2} \mathrm{~h}^{-1}$ ) and excellent selectivity (separation factor of 308) for ethanol dehydration through pervaporation.

Recently, desalination using TFNC membranes by the pervaporation process was demonstrated [98]. In this membrane system, a PVA top barrier layer was first electrosprayed on the aluminum foil and then a PAN nanofibrous scaffold was deposited by electrospinning as the mid-layer support. A PET non-woven substrate was subsequently applied as the bottom layer to complete the composite membrane. GA crosslinking was used to increase the water resistance of the PVA layer in the aqueous environment. During the pervaporation-driven desalination operation with $\mathrm{NaCl}$ solutions (the operating pressure was $100 \mathrm{~Pa}$ ), the membranes exhibited excellent desalina- 
tion performance (i.e., high water flux and salt rejection ratio $>99.5 \%$ ) for different salt concentrations with virtually no change in performance after $50 \mathrm{~h}$ of operation.

\section{Nanofibrous affinity membranes for adsorption}

Affinity membranes are a broad class of membranes that can selectively capture targeted molecules by immobilizing specific ligands onto the membrane surface. These membranes are developed to permit the purification of molecules based on differences in physical and chemical properties or biological functions rather than in molecular weight/size. As the affinity membranes require ligand molecules to be introduced into the inner surfaces of the membrane to capture targeted molecules, the structural characteristics of the electrospun scaffold are ideally suited for this purpose. These characteristics include the high surface area to volume ratio, high porosity and interconnectivity, good structural stability and controllable scaffold thickness. Thus far, affinity membranes based on surface functionalized electrospun nanofiber membranes have been demonstrated as effective heavy metal adsorption, organic waste adsorption or ion exchange media.

\section{Adsorption of heavy metal ions}

The discharge of wastewater, containing heavy metal ions, is a serious environment concern due to the high toxicity and accumulative characteristics nature in living organisms of these ions. The adsorption technique has been proven to be an effective means to remove heavy metal pollutants due to its simplicity, moderate operational conditions and economical feasibility. Nowadays, almost all adsorbents developed for the removal of heavy metal ions and dyes rely on the interactions of targeted compounds with functional groups that are present on the surface of the adsorbents [99*0. Therefore, a large surface area and abundant adsorption sites in the media are essential properties for adsorption affinity membranes. Compared with conventional absorbents, electrospun nanofiber membranes have unique properties, such as high specific surface area, high porosity and great potential to incorporate active functionality on nanoscale $[100,101]$. Therefore, nanofibrous affinity membranes offer an attractive alterative to the conventional adsorbents for the removal of heavy metal ions from wastewater. To increase the adsorption capacity of heavy metals using electrospun nanofiber membranes, three techniques have attracted a great deal of attention: (1) utilizing functional polymers that contain many desired functional groups 
for fabrication of the scaffolding materials; these polymers include silk fibroin, wool keratose, cellulose acetate, chitosan, and polyacrylic acid [24,102,103]; (2) surface modifications of electrospun nanofibers having active functional groups, such as amino groups, carboxylate groups, thiol groups, amide groups, sulfonate groups [24, 104,105]; (3) increasing the surface area of electrospun nanofibers [106,107].

In the adsorption process, the functional groups on the surface of the adsorbents played an important role in determining the effectiveness, capacity, selectivity, and reusability of the adsorbent materials. Natural polymeric nanofibers have been intensively investigated because of their abundance in nature, broad availability, and usefulness in practical applications. For example, chitosan (CS), one of the abundant of natural polysaccharides with hydrophilicity and charged characteristics, has emerged as a promising and effective nontoxic material for use in wastewater treatment. The electrospun CS nanofiber membranes neutralized with $\mathrm{K}_{2} \mathrm{CO}_{3}\left[103^{\circ}\right]$ exhibited the equilibrium adsorption capacity for $\mathrm{Cu}$ (II) of $485.44 \mathrm{mg} \mathrm{g}^{-1}$ and for $\mathrm{Pb}$ (II) of $263.15 \mathrm{mg} \mathrm{g}^{-1}$. The $\mathrm{Cu}(\mathrm{II})$ adsorption results were $\sim 6$ and $\sim 11$ times higher than the reported highest values of chitosan microspheres $\left(80.71 \mathrm{mg} \mathrm{g}^{-1}\right)$ and neat chitosan $\left(45.20 \mathrm{mg} \mathrm{g}^{-1}\right)$, respectively. The performance of chitosan/hydroxyapatite composite nanofiber membranes prepared by electrospinning was also investigated [108], where the adsorption studies showed that the maximum adsorption capacity of the membrane for lead, cobalt and nickel ions was in the following order: lead $(296.7 \mathrm{mg} / \mathrm{g})>$ cobalt $(213.8 \mathrm{mg} / \mathrm{g})>\operatorname{nickel}(180.2 \mathrm{mg} / \mathrm{g})$. Ki et al. [102] investigated the adsorption performance of nanofiber membranes made of a different type of natural polymer: wool keratose and silk fibroin blend, where the results showed that the membranes exhibited about 10 times higher $\mathrm{Cu}$ (II) adsorption capacity compared with the common fibrous filters (e.g., wool sliver and filter paper). The higher adsorption capacity could be attributed to the larger surface area and higher density of ionizable groups (i.e., wool keratose contains cysteine and hydrophilic amino acid). Another effective biopolymer tested was polyethylenimine (PEI), which is biological glue with an abundant amount of primary, secondary and tertiary amino groups. PEI has excellent adhesion capability with great affinity for various metal ions. Based on this material, Min et al [109] successfully fabricated crosslinked PEI/PVA nanofiber membranes using wetelectrospinning techniques. The resulting membranes were effective for heavy metal removal, where the results showed that the equilibrium absorption capacities for $\mathrm{Cu}(\mathrm{II}), \mathrm{Cd}(\mathrm{II}), \mathrm{Pb}(\mathrm{II})$ 
were $1.05 \mathrm{mmol} / \mathrm{g}, 1.04 \mathrm{mmol} / \mathrm{g}$ and $0.43 \mathrm{mmol} / \mathrm{g}$, respectively. Moreover, the used PEI/PVA nanofiber membranes could be regenerated successfully in EDTA aqueous solution.

Many functional polymers can't be electrospun directly and must be blended with other electrospinable polymers. This method is simple and easy to operate but will sacrifice a substantial portion of the adsorbent polymer, as it might be embedded inside the nanofibers. Surface modification of electrospun nanofibers with function groups can assure that the functional groups are located on the surface of nanofibers. Therefore, various functional groups such as carboxylate groups, sulfonate groups, amino groups, thiol groups, and special ligands, have been immobilized on the nanofiber surface to enable the adsorption capability. For example, the carboxylate groups could be produced by hydrolysis of the nitrile groups on electrospun PAN nanofibers [110] or the oxidization of electrospun cellulose nanofibers with $\mathrm{HNO}_{3} / \mathrm{H}_{3} \mathrm{PO}_{4}-\mathrm{NaNO}_{2}$ solutions [111], where the resulting membranes with negatively charged carboxylate groups exhibited very high adsorption capacity against the various heavy metal ions (positively charged). The nitrile groups on electrospun PAN nanofibers could also be chemically modified with hydroxylamine [112], hydrazine [113], and diethylenetriamine [114]. For example, amidoxime-modified PAN nanofibers were prepared by reacting PAN with hydroxylamine hydrochloride, where the resulting membranes could be used as a media for metal ions chelation [112]. The saturated coordinate capacities of the resultant nanofiber membranes against $\mathrm{Cu}^{2+}, \mathrm{Cd}^{2+}$ were 3.4482 and 4.5408 $\mathrm{mmol} / \mathrm{g}$, respectively, where these values were about 2 times higher than those of conventional fibers based on amidoxime ployacrylonitrile. Li et al [101] reported on the efficient adsorption of gold ions from aqueous systems using thioamide-group chelating nanofiber membranes, where the membranes were prepared by using the combined electrospinning and chemical modification process. The resulting nanofiber membranes displayed a high adsorption efficiency for Au(III) ions, and the maximum adsorption capacity of the chelating nanofibers toward Au(III) ions at different temperatures were $15.86 \mathrm{mmol} / \mathrm{g}(298 \mathrm{~K}), 23.50 \mathrm{mmol} / \mathrm{g}(323 \mathrm{~K})$ and $34.60 \mathrm{mmol} / \mathrm{g}$ (348 K).

The specific surface area is an important factor that can affect the adsorption capacity of the adsorbent. In order to obtain a nanofiber membrane with ultra-high specific surface area, it's desirable to introduce rough surface or pore structure on the fiber surface. One technique to add extra surface area in the nanofibrous scaffold is through the introduction of "micro-nano" structure on 
the fiber surface (Figure 10). To fabricate such affinity membranes, mixtures of PES and PEI were electrospun followed by solvent etching in a crosslinking solution of PEI. Stable nanoscaled PEI spherules $(\sim 200 \mathrm{~nm})$ were subsequently formed on the surface of electrospun nanofibrous scaffold due to the phase separation of PEI and PES. This unique fiber morphology provided significantly large PEI surface area per unit mass, and high effectiveness for heavy metal ions removal from water [99*0]. The fabrication of porous nanofibers in the electrospun scaffold is another way to prepare highly efficient medium to adsorb heavy metal ions. With this approach, Taha et al $\left[115^{\circ}\right]$ prepared a series of $\mathrm{PVP} / \mathrm{SiO}_{2}$ nanofibrous affinity membranes by electrospinning of mixtures of PVP, tetraethyl orthosilicate and cetyltrimethyl ammonium bromide (as the structure directing agent), where the resulting membranes contained abundant amino groups and mesostructure on the nanofibers. The resultant membranes exhibited very high adsorption capacity toward $\mathrm{Cr}^{3+}$ ions. Similarly, Wu et al [107] utilized thiol-functionalized $\mathrm{PVA} / \mathrm{SiO}_{2}$ nanofiber membranes for removal of $\mathrm{Cu}$ (II) from waste water, where the surface area

of the membrane was larger than $290 \mathrm{~m}^{2} / \mathrm{g}$. The best performing membrane exhibited the adsorption capacity for $\mathrm{Cu}$ (II) of $489.12 \mathrm{mg} / \mathrm{g}$, which was higher than any other reported nanofiber affinity membranes.

\section{Adsorption of organic compounds}

Organic compounds, like spilt oil, dyes, bio-therapeutic products and other organic contaminants, are harmful to the environment and the human health. Nanofibrous affinity membranes have also been considered as promising adsorbents for the removal of organic contaminants due to the large surface area, high porosity, controllable pore structure, and available surface functionalization schemes to modify nanofiber membranes.

Polystyrene (PS), a hydrophobic-oleophilic material, has been widely used in electrospinning of nanofibrous oil absorbent [116-118]. For example, Lin and co-workers fabricated a series of micro/nano-structured electrospun PS nanofiber membranes (Figure 11) via adjusting the polymer molecular weight, solvent composition, and solution concentration. The resulting PS membranes exhibited the absorption capacity of 84.41 and $79.62 \mathrm{~g} / \mathrm{g}$ for motor oil and sunflower seed oil, respectively, which were nearly 3 times larger than those of commercial PP non-woven fabrics [118]. In order to improve the mechanical properties of these membranes, electrospun nanofibers 
made of PS and polyurethane (PU) blends [119] or PS and polyvinyl chloride (PVC) blends [120], co-axially electrospun PS/PU nanofibers [121] and carbon nanofibrous films [122] were investigated comprehensively, which all showed excellent oil sorption capacities.

Nanofibrous affinity membranes are also ideal media to remove dye molecules from wastewater. For example, Si and co-workers [123-125] fabricated hierarchical, porous, and functional nanofiber membranes containing magnetic $\mathrm{Fe}_{3} \mathrm{O}_{4} @$ carbon nanofibers $\left(\mathrm{Fe}_{3} \mathrm{O}_{4} @ \mathrm{CNF}\right)$ using a combination of electrospinning and in situ polymerization technique with polybenzoxazine precursors. The as-prepared membranes containing $\mathrm{Fe}_{3} \mathrm{O}_{4} / \mathrm{CNFs}$ possessed an extremely high surface area of $1885 \mathrm{~m}^{2} / \mathrm{g}$ and the porosity of $2.325 \mathrm{~cm}^{3} / \mathrm{g}$, and exhibited efficient adsorption for organic dyes in water as well as excellent magnetic separation performance. Various modification strategies have also been demonstrated to introduce large functional sites on the nanofiber surface to improve the dye removal efficiency. As described earlier, Min and co-workers [99 ${ }^{\circ}$ ] fabricated a novel micro/nano-structured PES/PEI nanofiber membrane system, containing large amino and imino groups, effective for metal ion removal. This membrane system was also effective to remove some dye molecules with the maximum adsorption capacities for Sunset Yellow FCF, Fast Green FCF and Amaranth as of 1000.00, 344.83 and $454.44 \mathrm{mg} / \mathrm{g}$, respectively. Miao and co-workers [126] demonstrated another type of hierarchical $\mathrm{SiO}_{2} @ \gamma-\mathrm{AlOOH}$ (Boehmite) core/sheath nanofiber membranes based on the combination of electrospinning and hydrothermal reaction (Figure 12), where the resulting membrane exhibited an efficient adsorption for Congo red. Other electrospun absorbents, like the thiol-functionalized polyvinyl alcohol (PVA)/ $\mathrm{SiO}_{2}$ composite nanofiber membranes [127], and mesoporous carbon nanofibers fabricated by a sol-gel electrospinning process (using phenolic resin precursor as the carbon source, and triblock copolymer Pluronic ${ }^{\circledR}$ F127 as the template) [128], were also demonstrated for the adsorption of various dye molecules.

In addition to adsorbing dyes, nanofiber affinity membranes have also been utilized for efficient removal of other organic compounds, such as protein (bovine serum albumin (BSA), lysozyme) [129-131] and dieldrin [132]. For example, Yue and co-workers [132] fabricated a novel bromopropyl functionalized silica-based nanofiber membranes for the removal of persistent organic pollutants (POPs). Because of the large specific surface area and large amount of pores, the bromopropyl modified silica nanofibers were found to be highly effective to remove hydrophobic 
dieldrin from micro-polluted water, especially at low concentrations. Its removal rate was estimated to be $91.02 \%$, much higher than that of the unmodified silica nanofiber membrane (20.93 $\%)$ as well as the commercially used granular activated carbon (38.65\%).

\section{Ion exchange membranes}

Ion exchange membranes (IEMs) have been widely used for the ionic separation processes, such as electro-dialytic separation, diffusion dialysis, alkali and transition metal ion recovery, fuel cells, and etc. Recently, a novel fabrication method of IEMs based on electrospinning technique has attracted a great deal of attention since the resulting membranes have high aspect ratio, interconnected porous structure, large specific surface area, and flexibility to produce conductive nanofibers.

Chakrabartya and co-workers [133 $]$ reported the fabrication of electrospun sulfonated poly(ether ether ketone) (SPEEK) nanofiber membranes for electro-dialytic separation of $\mathrm{Na}^{+}$from $\mathrm{Mg}^{2+}$ or $\mathrm{Ca}^{2+}$ ions. It was found that SPEEK nanofiber membranes exhibited very low flux and electrotransport efficiency for divalent cations in comparison with $\mathrm{Na}^{+}$, making it a promising candidate for purifying brackish water into potable drinking water from and for application in the chloralkali industry. Pan and co-workers [134] have fabricated a cation exchange nanofiber membrane by electrospinning sulfonated poly(phenyleneoxide) (SPPO) followed by the hot-press treatment. The resulting membrane exhibited higher hydroxide permeability $\left(\mathrm{U}_{\mathrm{OH}}=0.00971 \mathrm{~m} / \mathrm{h}\right)$ and separation factor $(\mathrm{S}=36.09)$ than the solution cast SPPO membrane (CSPPO, $\mathrm{U}_{\mathrm{OH}}=0.00605 \mathrm{~m} / \mathrm{h}$ and $\mathrm{S}=21.8$ ) to recover alkali from $\mathrm{Na}_{2} \mathrm{WO}_{4} / \mathrm{NaOH}$ solution by diffusion dialysis.

In addition, IEMs for fuel cell applications have also gained much attention. For example, Choi and co-workers [135] demonstrated the fabrication of sulfonated poly(arylene ether sulfone) (sPAES) electrospun proton exchange nanofiber membrane having an inert/uncharged polymer filling the interfibrous voids. Park and co-workers [136 $]$ also fabricated a family of highly conductive and mechanically robust anion exchange membranes with unique cross-linked nanofiber composite morphology for alkaline fuel cell applications. To produce such membranes, precursor polymer solutions, including tetramethylammonium ionomer and chloromethylated polysulfone (CMPSF), and an inert reinforcing polymer, poly(phenylsulfone) (PPSF), were electrospun from separate spinnerets into dual nanofiber scaffolds. The resultant network of ionomer containing 
nanofibers embedded in a PPSF matrix appeared to be an ideal IEM, exhibiting a very high ion exchange capacity $(3.1 \mathrm{mmol} / \mathrm{g})$, with $\mathrm{OH}^{-}$conductivity of $65 \mathrm{mS} / \mathrm{cm}$ in water, stress at break of $14 \mathrm{MPa}$, and equilibrium liquid water swelling of $144 \%$ at $23{ }^{\circ} \mathrm{C}$. Similarly, Wang and coworkers [137] also demonstrated the fabrication of an anion exchange membrane by electrospinning of poly(aryl ether sulfone) having hexaalkyl guanidinium side chain groups (PES-G-Cl) and (vinylbenzyl) trimethylammonium chloride (VBTC) ionomers. This membrane system is also suitable for fuel cell applications.

\section{Conclusions and future outlook}

Nanofiber membranes offer some unique advantages over conventional membranes, owing to their high surface-to-volume ratio, adjustable interconnected pore sizes and easy surface modification schemes. These membranes are ideal candidates to deal with many emerging environmental challenges such as air pollution and water contamination problems. The electrospinning technology has been proven to be a very versatile technique to fabricate highly porous nanofiber membranes from a very large selection of materials. The combination of innovative and scalable electrospinning process and flexible surface treatments (e.g., chemical modification, plasma treatment, ultrathin coating, and so on) make it particularly suitable to fabricate water filtration membranes for applications in microfiltration, ultrafiltration, nanofiltration and reverse osmosis. In this review, the advances of using electrospun nanofiber membranes for a wide range of membrane applications, plus pervaporation and adsorption, for water purification are discussed. It is clear that the selection of suitable materials and appropriate incorporation routes to introduce the desired functionality, during or after electrospinning, are critical to produce the appropriate nanofiber membrane system to meet the specific needs.

The future outlook of using electrospun nanofiber membranes, especially with those capable of dealing with water remediation challenges, is extremely bright. However, different from air filtration membranes, the quality requirement for water filtration membrane is also higher. This suggests that the precise control of membrane uniformity, pore size distribution, barrier layer and support layer thicknesses must be achieved by electrospinning in industrial scale. Without question, electrospun nanofibrous membranes have already become an extremely promising platform for many different separation and purification applications. 


\section{Acknowledgement}

X.W. would like to acknowledge the financial support from the National Science Foundation of China (51273042 and 21174028) and Program of Shanghai Science and Technology Innovation International Exchange and Cooperation (15230724700), and B.S.H. would like to thank the financial support from the SusChEM Program of the National Science Foundation in the U.S. (DMR-1409507).

\section{References}

[1] Reneker DH, Chun I: Nanometer diameter fibers of polymer, produced by electrospinning. Nanotechnology 1996, 7: 216-223.

[2] Li D, Xia YN: Electrospinning of nanofibers: reinventing the wheel? Adv Mater 2004, 16: 1151-1170.

[3] Huang Z, Zhang Y, Kotaki, Ramakrishna S: A review on polymer nanofibers by electrospinning and their applications in nanocomposites. Compos Sci Technol 2003, 63:2223-2253.

[4] Zhou F, Gong R: Manufacturing technologies of polymeric nanofibres and nanofibre yarns. Polym Int 2008, 57:837-845.

[5] Pike RD: Superfine microfiber nonwoven web. US Patent 5,935,883. 1999.

[6] Feng L, Li S, Li H, Zhai J, Song Y, Jiang L, Zhu D: Superhydrophobic surface of aligned polyacrylonitrile nanofibers. Angew Chem Int Ed 2002, 41:1221-1223.

[7] Martin CR: Membrane-based synthesis of nanomaterials. Chem Mater 1996, 8:1739-1746.

[8] Huie JC: Guided molecular self-assembly: a review of recent efforts. Smart Mater Struct 2003, 12:264-271.

[9] Faul CFJ, Antonietti M: Ionic self-assembly: facile synthesis of supramolecular materials. Adv Mater 2003, 15:673-683. 
$\left[9^{\circ}\right]$ The technique of ionic self-assembly, a powerful tool to create new material nanostructures and chemical objects, is reviewed from various aspects.

[10] Tseng AA, Notargiacomo A, Chen TP: Recent developments in nanofabrication using scanning near-field optical microscope lithography. J Vac Sci Technol B 2005, 23:877-894.

[11] Wouter D, Schubert US: Nanolithography and nanochemistry: probe-related patterning techniques and chemical modification for nanometer-sized devices. Angew Chem Int Ed 2004, 43:2480-2495.

[12] Hull PJ, Hutchison JL, Salata OV, Dobson PJ: Synthesis of nanometer-scale silver crystallites via a room-temperature electrostatic spraying process. Adv Mater 1997, 9:413-417.

[13] Formalas: Process and apparatus for preparing artificial threads. US patent 1,975,504. 1934.

[14] Zachariades AE, Porter RS, Doshi J, Srinivasan G, Reneker DH: A novel electrospinning process. Polym News 1995, 20:206-207.

[15] Greiner A, Wendorff JH: Electrospinning: A fascinating method for the preparation of ultrathin fibers. Angew Chem Int Ed 2007, 46:5670-5703.

[16] Feng C, Khulbe K.C, Matsuura T, Tabe S, Ismail AF: Preparation and characterization of electro-spun nanofiber membranes and their possible applications in water treatment. Sep Purif Technol 2013, 102:118-135.

[17] Burger C, Hsiao BS, Chu B: Nanofibrous materials and their applications. Annu Rev Mater Res 2006, 36:333-368.

[18] Thavasi V, Singh G, Ramakrishna S: Electrospun nanofibers in energy and environmental applications. Energy Environ Sci 2008, 1:205-221.

[19] Wu J, Wang N, Zhao Y, Jiang L: Electrospinning of multilevel structured functional micro-/nanofibers and their applications. J Mater Chem A 2013, 1:7290-7305. 
[20] Barhate RS, Ramakrishna S: Nanofibrous filtering media: Filtration problems and solutions from tiny materials. J Membr Sci 2007, 296:1-8.

[21] Kaur S, Sundarrajan S, Rana D, Sridhar R, Gopal R, Matsuura T, Ramakrishna S: Review: the characterization of electrospun nanofibrous liquid filtration membranes. J Mater Sci 2014, 49:6143-6159.

[22] Homaeigohar S, Elbahri M: Nanocomposite Electrospun Nanofiber Membranes for Environmental Remediation. Materials 2014, 7:1017-1045.

[23] Nasreen SAAN, Sundarrajan S, Syed AS, Balamurugan R, Ramakrishna S: Advancement in Electrospun Nanofiber membranes Modification and Their Application in Water Treatment. Membranes 2013, 3:266-284.

[24] Ma HY, Hsiao BS, Chu B: Electrospun Nanofiber membrane for Heavy Metal Ion Adsorption. Curr Org Chem 2013, 17:1361-1370.

[25] Thompson CJ, Chase GG, Yarin AL, Reneker DH: Effects of parameters on nanofiber diameter determined from electrospinning model. Polymer 2007, 48:6913-6922.

[26] Tripatanasuwan S, Zhong ZX, Reneker DH: Effect of evaporation and solidification of the charged jet in electrospinning of poly(ethylene oxide) aqueous solution. Polymer 2007, 48:5742-5746.

[27] Casper CL, Stephens JS, Tassi NG, Chase DB, Rabolt JF: Controlling surface morphology of electrospun polystyrene fibers: effect of humidity and molecular weight in electrospinning process. Macromolecules 2004, 37:573-578.

[28] Bognitzki M, Czado W, Frese T, Schaper A, Hellwig M, Steinhart M, Greiner A, Wendorff JH: Nanostructured fibers via electrospinning. Adv Mater 2001, 13:70-72.

[29] Chu B, Hsiao BS, Fang D: Apparatus and methods for electrospinning polymeric fibers and membranes. US Patent 6,713,011. 2004. 
[30 ] Dosunmu OO, Chase GG, Kataphinan W, Reneker DH: Electrospinning of polymer nanofibres from multiple jets on a porous tubular surface. Nanotechnology 2006, 17:11231127.

$\left[30^{\circ}\right]$ The authors demonstrated a device for multiple-jet electrospinning from a cylindrical porous tube. The porous tube has a significantly higher production rate over the single needle, where their fiber size distributions on a length-weighted basis are similar but the porous tube produces fibers with a broader distribution.

[31] Chen Y, Yu H, Zhang Y, Zhang K: Atmosphere controllable electrospinning device and method. China, Patent No. CN1876902B. 2010.

[32] Wang X, Chen Y, Zhou Z, Yang Y, Li X: Three-dimensional type multi-spinning-nozzle spinneret plate for electrospinning. China, Patent No. CN203451652U. 2014.

[33] Chu B, Hsiao BS, Fang D: Apparatus for electro-blowing or blowing-assisted electrospinning technology and process for post treatment of electrospun or electro-blown membranes. US Patent Appl 12, 236,011. 2008.

[34] Um IC, Fang D, Hsiao BS, Okamoto A, Chu B: Electro-spinning and electro-blowing of hyaluronic acid. Biomacromolecules 2004, 5:1428-1436.

[35] Wang X, Um IC, Fang D, Okamoto A, Hsiao BS, Chu B: Formation of water-resistant hyaluronic acid nanofibers by blowing-assisted electrospinning and non-toxic post treatments. Polymer 2005, 46:4853-4867.

[36] Barhate R, Loong CK, Ramakrishna S: Preparation and characterization of nanofibrous filtering media. J Membr Sci 2006, 283:209-218.

[37] Gopal R, Kaur S. Ma Z, Chan C, Ramakrishna S, Matsuura T: Electrospun nanofibrous filtration membrane. J Membr Sci 2006, 281:581-586.

[38] Gopal R, Kaur S, Feng CY, Chan C, Krishna S, Tabe S, Matsuura T: Electrospun nanofibrous polysulfone membranes as pre-filters: Particulate removal. J Membr Sci 2007, 289:210-219. 
[39] Aussawasathien D, Teerawattananon C, Vongachariya A: Separation of micron to submicron particles from water: Electrospun nylon-6 nanofiber membranes as pre-filters. J Membr Sci 2008, 315:11-9.

[40 ${ }^{\circ}$ Veleirinho B, Lopes-da-Silva JA: Application of electrospun poly(ethylene terephthalate) nanofiber mat to apple juice clarification. Process Biochem 2009, 44:353-356.

$\left[40^{\circ}\right]$ Electrospun PET nanofiber membranes was used for apple juice clarification and showed a higher flux performance, i.e., faster, simpler and more cost-effective than the conventional system, offering new application opportunities for the juice processing industry or even for other food industry fields

[41] Liu Y, Wang R, Ma H, Hsiao BS, Chu B: High-flux microfiltration filters based on electrospun polyvinylalcohol nanofiber membranes. Polymer 2013, 54:548-556.

[42] Barhate R, Ramakrishna S: Nanofibrous filtering media: filtration problems and solutions from tiny materials. J Membr Sci 2007, 296:1-8.

[43] Ma H, Burger C, Hsiao BS, Chu B: Ultra-fine cellulose nanofibers: new nano-scale materials for water purification. J Mater Chem 2011, 21:7507-7510.

[44] Wang R, Liu Y, Li B, Hsiao BS, Chu B: (2012) Electrospun nanofiber membranes for high flux microfiltration. J Membr Sci 392-393:167-174.

$\left[44^{\circ}\right]$ The relationships between the structural parameters of electrospun nanofibrous membranes and microfiltration performance for water purification were studied systematically in this paper.

[45] Sato A, Wang R, Ma HY, Hsiao BS, Chu B: Novel nanofibrous scaffolds for water filtration with bacteria and virus removal capability. J Electron Microsc 2011, 60:201-209.

[46] Ma HY, Burger C, Hsiao BS, Chu B: Nanofibrous Microfiltration Membrane Based on Cellulose Nanowhiskers. Biomacromolecules 2012, 13:180-186. 
[47] Wang R, Guan S, Sato A, Wang X, Wang Z, Yang R, Hsiao BS, Chu B: Nanofibrous microfiltration membranes capable of removing bacteria, viruses and heavy metal ions. J Membr Sci 2013, 446:376-382.

[48] Ma HY, Hsiao BS, Chu B: Functionalized electrospun nanofibrous microfiltration membranes for removal of bacteria and viruses. J Membr Sci 2014, 452:446-452.

[49] Tuteja A, Choi W, Ma ML, Mabry JM, Mazzella SA, Rutledge GC, McKinley GH, Cohen RE: Designing superoleophobic surfaces. Science 2007, 318:1618-1622.

[50] Lee MW, An S, Latthe SS, Lee C, Hong S, Yoon SS: Electrospun polystyrene nanofiber membrane with superhydrophobicity and superoleophilicity for selective separation of water and low viscous oil. ACS Appl Mater Interfaces 2013, 5:10597-10604.

[51] Tai MH, Gao P, Tan BYL, Sun DD, Leckie JO: Highly efficient and flexible electrospun carbon-silica nanofiber membrane for ultrafast gravity-driven oil-water separation. ACS Appl Mater Interfaces 2014, 6:9393-9401.

[52] Li X, Wang M, Wang C, Cheng C, Wang X: Facile immobilization of Ag nanocluster on nanofiber membrane for oil/water separation. ACS Appl Mater Interfaces 2014, 6:1527215282.

[53] Shang Y, Si Y, Raza A, Yang L, Mao X, Ding B, Yu J: An in situ polymerization approach for the synthesis of superhydrophobic and superoleophilic nanofiber membranes for oil-water separation. Nanoscale 2012, 4:7847-7854.

[54] Tang X, Si Y, Ge J, Ding B, Liu L, Zheng G, Luo W, Yu J: In situ polymerized superhydrophobic and superoleophilic nanofiber membranes for gravity driven oil-water separation. Nanoscale 2013, 5:11657-11664.

[55] Ahmed FE, Lalia BS, Hilal N, Hashaikeh R: Underwater superoleophobic cellulose/electrospun PVDF-HFP membranes for efficient oil/water separation. Desalination 2014, 344:48-54. 
[56] Huang M, Si Y, Tang X, Zhu Z, Ding B, Liu L, Zheng G, Luo W, Yu J: Gravity driven separation of emulsified oil-water mixtures utilizing in situ polymerized superhydrophobic and superoleophilic nanofiber membranes. J Mater Chem A 2013, 1:14071-14074.

[57] Raza A, Ding B, Zainab G, El-Newehy M, Al-Deyab SS, Yu J: In situ cross-linked superwetting nanofiber membranes for ultrafast oil-water separation. J Mater Chem A 2014, 2:10137-10145.

[58 ${ }^{\circ}$ Y Yang S, Si Y, Fu Q, Hong F, Yu J, Al-Deyab SS, El-Newehy M, Ding B: Superwetting hierarchical porous silica nanofiber membranes for oil/water microemulsion separation. Nanoscale 2014, 6:12445-12449.

$\left[58^{\circ}\right]$ Herarchical porous silica nanofibrous membranes with superhydrophilicity and underwater superoleophobicity were prepared in this paper; these membranes can effectively separate oil-inwater microemulsions through gravity and exhibit an extremely high flux.

[59] Khayet M: Membranes and theoretical modeling of membrane distillation: A review. Adv Colloid Interface Sci 2011, 164:56-88.

[60] Feng C, Khulbe KC, Matsuura T, Gopal R, Kaur S, Ramakrishna S, Khayet M: Production of drinking water from saline water by air-gap membrane distillation using polyvinylidene fluoride nanofiber membrane. J Membr Sci 2008, 311:1-6.

[61] Essalhi M, Khayet M: Self-sustained webs of polyvinylidene fluoride electrospun nanofibers: Effects of polymer concentration and desalination by direct contact membrane distillation. J Membr Sci 2014, 454:133-143.

$\left[61^{\circ}\right]$ This paper discussed the effects of PVDF concentration on the characteristics and direct contact membrane distillation (DCMD) desalination performance of self-sustained electrospun nanofibrous membranes.

[62] Liao Y, Wang R, Tian M, Qiu C, Fane AG: Fabrication of polyvinylidene fluoride (PVDF) nanofiber membranes by electro-spinning for direct contact membrane distillation. J Membr Sci 2013, 425:30-39. 
[63] Essalhi M, Khayet M: Self-sustained webs of polyvinylidene fluoride electrospun nanofibers at different electrospinning times: 1. Desalination by direct contact membrane distillation. J Membr Sci 2013, 433:167-179.

$\left[63^{\circ}\right]$ The effects of membrane thickness on the DCMD performance is carried out for the first time, and the permeate flux did not decline linearly with the thickness of the electrospun nanofibrous membranes. This is attributed to the decrease of the energy lost by heat conduction through the electrospun nanofibrous membranes with the increase of the membrane thickness.

[64] Wu HY, Wang R, Field RW: Direct contact membrane distillation: An experimental and analytical investigation of the effect of membrane thickness upon transmembrane flux. J Membr Sci 2014, 470:257-265.

[64 $\left.{ }^{\circ}\right]$ Polyvinylidene fluoride electrospun nanofibrous membranes with various thicknesses were fabricated and tested in a DCMD cell at five different operating conditions in order to demonstrate the optimal membrane thickness.

[65] Lalia BS, Guillen-Burrieza E, Arafat HA, Hashaikeh R: Fabrication and characterization of polyvinylidenefluoride-co-hexafluoropropylene (PVDF-HFP) electrospun membranes for direct contact membrane distillation. J Membr Sci 2013, 428:104-115.

[66] Lalia BS, Guillen E, Arafat HA, Hashaikeh R: Nanocrystalline cellulose reinforced PVDF-HFP membranes for membrane distillation application. Desalination 2014, 332:134141 .

[67] Prince JA, Singh G, Rana D, Matsuura T, Anbharasi V, Shanmugasundaram TS: Preparation and characterization of highly hydrophobic poly(vinylidene fluoride) - Clay nanocomposite nanofiber membranes (PVDF-clay NNMs) for desalination using direct contact membrane distillation. J Membr Sci 2012, 397:80-86.

[68] Dong ZQ, Ma XH, Xu ZL, You WT, Li Fb: Superhydrophobic PVDF-PTFE electrospun nanofiber membranes for desalination by vacuum membrane distillation. Desalination 2014, 347:175-183. 
[69] Liao Y, Wang R, Fane AG: Engineering superhydrophobic surface on poly(vinylidene fluoride) nanofiber membranes for direct contact membrane distillation. J Membr Sci 2013, 440:77-87.

[70] Liao Y, Wang R, Fane AG: Fabrication of Bioinspired Composite Nanofiber Membranes with Robust Superhydrophobicity for Direct Contact Membrane Distillation. Environ Sci Technol 2014, 48:6335-6341.

$\left[70^{\circ}\right]$ Self-cleaning composite nanofiber membrane system, consisting of a superhydrophobic silica-PVDF composite selective skin on the PVDF nanofibrous scaffold, was prepared. The project was inspiring by the surface characteristics of lotus leaf.

[71“] Liao Y, Loh CH, Wang R, Fane AG: Electrospun Superhydrophobic Membranes with Unique Structures for Membrane Distillation. ACS Appl Mater Interfaces 2014, 6:1603516048 .

[71 ${ }^{\circ *}$ ] This study demonstrated novel design strategies for highly robust superhydrophobic duallayer membranes for MD via electrospinning inspired by the lotus leaf.

[72] Maab H, Francis L, Al-Saadi A, Aubry C, Ghaffour N, Amy G, Nunes SP: Synthesis and fabrication of nanostructured hydrophobic polyazole membranes for low-energy water recovery. J Membr Sci 2012, 423:11-19.

[73] Zhou T, Yao Y, Xiang R, Wu Y: Formation and characterization of polytetrafluoroethylene nanofiber membranes for vacuum membrane distillation. J Membr Sci 2014, 453:402-408.

[74] Li X, Wang C, Yang Y, Wang X, Zhu M, Hsiao BS: Dual-Biomimetic Superhydrophobic Electrospun Polystyrene Nanofiber membranes for Membrane Distillation. ACS Appl Mater Interfaces 2014, 6:2421-2428.

[75] Yoon K, Kim K, Wang X, Fang D, Hsiao BS, Chu B: High flux ultrafiltration membranes based on electrospun nanofibrous PAN scaffolds and chitosan coating. Polymer 2006, 47:2434-2441. 
[76] Wang X, Fang D, Yoon K, Hsiao BS, Chu B: High performance ultrafiltration composite membranes based on poly(vinyl alcohol) hydrogel coating on crosslinked nanofibrous poly(vinyl alcohol) scaffold. J Membr Sci 2006, 278:261-268.

[77] Wang X, Chen X, Yoon K, Fang D, Hsiao BS, Chu B: High flux filtration medium based on nanofibrous substrate with hydrophilic nanocomposite coating. Environ Sci Technol 2005, 39:7684-7691.

[77 $]$ The authors prepared hydrophilic nanocomposite coating barrier layer on the electrospun nanofibrous substrate for the first time. The resulting membrane exhibited a higher flux than conventional membranes and an excellent total organic solute rejection rate without appreciable fouling.

[78“] Ma HY, Burger C, Hsiao BS, Chu B: Ultrafine polysaccharide nanofibrous membranes for water purification. Biomacromolecules 2011, 12: 970-976.

[78"] The TFNC membrane prepared in this article exhibited a 10-fold higher permeation flux than a commercial UF membrane by using ultrafine polysaccharide nanofibrous membranes for separation of oil emulsions and water, while retaining the same rejection ratio (above 99.5\%).

[79] Ma HY, Burger C, Hsiao BS, Chu B: Ultra-fine cellulose nanofibers: new nano-scale materials for water purification. J Mater Chem 2011, 21: 7507-7510.

[79 ] Ultra-fine cellulose nanofibers were used as the barrier layer in an asymmetric threelayered non-woven fibrous format, containing fibers of different diameters (from $5 \mathrm{~nm}$ to 20 $\mu \mathrm{m})$. The resultant membranes exhibited a two- to ten-fold increase in permeation flux over commercial membranes for ultrafiltration of oil and water emulsions.

[80] Ma HY, Burger C, Hsiao BS, Chu B: Fabrication and characterization of cellulose nanofiber based thin-film nanofibrous composite membranes. J Membr Sci 2014, 454: 272 282.

[81] Ma HY, Hsiao BS, Chu B: Thin-film nanofibrous composite membranes containing cellulose or chitin barrier layers fabricated by ionic liquids. Polymer 2011, 52:2594-2599. 
[81 $]$ Novel high-flux TFNC membranes with regenerated cellulose, chitin, and cellulose-chitin blend barrier layers were fabricated from non-derivative solvent-ionic liquid and applied for ultrafiltration of an oil/water emulsion. The membranes exhibited five- to ten-fold increases in permeation flux when compared with that of a commercial ultrafiltration membrane, implying the practical feasibility of such polysaccharide membranes for UF applications

[82] Yoon Y, Hsiao BS, Chu B High flux ultrafiltration nanofiber membranes based on polyacrylonitrile electrospun scaffolds and crosslinked polyvinyl alcohol coating. J Membr Sci 2009, 338:145-152.

[83] Ma HY, Yoon K, Rong LX, Mao YM, Mo ZR, Fang DF, Hollander Z, Gaiteri J, Hsiao BS, Chu B: High-flux thin-film nanofibrous composite ultrafiltration membranes containing cellulose barrier layer. J Mater Chem 2010, 20:4692-4704.

[84] Tang Z, Wei J, Yung L, Ji B, Ma H, Qiu C, Yoon K, Wan F, Fang D, Hsiao BS, Chu B: UV-cured poly(vinyl alcohol) ultrafiltration nanofiber membrane based on electrospun nanofiber scaffolds. J Membr Sci 2009, 328:1-5.

[85"] Wang XF, Zhang K, Yang Y, Wang LL, Zhou Z, Zhu MF, Hsiao BS, Chu B: Development of hydrophilic barrier layer on nanofibrous substrate as composite membrane via a facile route. J Membr Sci 2010, 356:110-116.

$\left[85^{\circ}\right]$ This paper demonstrated a unique technique to prepare an ultra-thin barrier layer on the nanofibrous scaffold to avoid the penetration of the coating solution into the nanofibrous scaffold.

[86 ${ }^{\circ}$ You H, Yang Y, Li X, Zhang K, Wang XF, Zhu MF, Hsiao BS: Low pressure high flux thin film nanofibrous composite membranes prepared by electrospraying technique combined with solution treatment. J Membr Sci 2012, 394:241-247.

[86 $]$ A novel solution treatment was demonstrated to prepare an ultra-thin barrier layer on the nanofibrous scaffold by combined with the electrospraying technique.

[87] You H, Li X, Yang Y, Wang BY, Li ZX, Wang XF, Zhu MF, Hsiao BS: High flux low pressure thin film nanocomposite ultrafiltration membranes based on nanofibrous substrates. Sep Purif Technol 2013, 108:143-151. 
[88] Subramanian S, Seeram R: New directions in nanofiltration applications - Are nanofibers the right materials as membranes in desalination? Desalination 2013, 308:198208.

[89] Yoon K, Hsiao BS, Chu B: High flux nanofiltration membranes based on interfacially polymerized polyamide barrier layer on polyacrylonitrile nanofibrous scaffolds. J Membr Sci 2009, 326:484-492.

[90] Yung L, Ma HY, Wang X, Yoon K, Wang R, Hsiao BS, Chu B: Fabrication of thin-film nanofibrous composite membranes by interfacial polymerization using ionic liquids as additives. J Membr Sci 2010, 365:52-58.

[91] Tang ZH, Qiu CQ, McCutcheon JR, Yoon K, Ma HY, Fang DF, Lee E, Kopp C, Hsiao BS, Chu B: Design and Fabrication of Electrospun Polyethersulfone Nanofibrous Scaffold for High-Flux Nanofiltration Membranes. J Polym Sci Polym Phys 2009, 47:2288-2300.

[92] Yoon K, Hsiao BS, Chu B: Formation of functional polyethersulfone electrospun membrane for water purification by mixed solvent and oxidation processes. Polymer 2009, 50:2893-2899.

[93] Zhang HY, Zheng JF, Zhao ZG, Han CC: Role of wettability in interfacial polymerization based on PVDF electrospun nanofibrous scaffolds. J Membr Sci 2013, 442:124-130.

[94] Wang X, Yeh TM, Wang Z, Yang R, Wang R, Ma HY, Hsiao BS, Chu B: Nanofiltration membranes prepared by interfacial polymerization on thin-film nanofibrous composite scaffold. Polymer 2014, 55:1358-1366.

[95] Wang X, Fang DF, Hsiao BS, Chu B: Nanofiltration membranes based on thin-film nanofibrous composites. J Membr Sci 2014, 469:188-197.

[96] Yeh TM, Yang L, Wang X, Mahajan D, Hsiao BS, Chu B: Polymeric nanofibrous composite membranes for energy efficient ethanol dehydration. J Renew Sustain Ener 2012, 4:041406. 
[97] Yeh TM, Wang Z, Mahajan D, Hsiao BS, Chu B: High flux ethanol dehydration using nanofiber membranes containing graphene oxide barrier layers. J Mater Chem A 2013, 1:12998-13003.

[98] Liang B, Pan K, Li L, Giannelis EP, Cao B: High performance hydrophilic pervaporation composite membranes for water desalination. Desalination 2014, 347:199206.

[99“] Min MH, Shen LD, Hong GH, Zhu MF, Zhang Y, Wang XF, Chen YM, Hisao BS: Micronano structure poly(ether sulfones)/poly(ethyleneimine) nanofibrous affinity membranes for adsorption of anionic dyes and heavy metal ions in aqueous solution. Chem Eng J 2012, 197:88-100.

[99"] One technique to introduce extra surface area in the nanofibrous scaffold is proposed here through the introduction of "micro-nano" structure on the fiber surface to increase the adsorption capacity of the adsorbent.

[100] Sang Y, Gu Q, Sun T, Li F, Liang C: Filtration by a novel nanofiber membrane and alumina adsorption to remove copper(II) from groundwater. J Hazard Mater 2008, 153:860866.

[101] Li X, Zhang C, Zhao R, Liu X, Xu X, Jia X, Wang C, Li L: Efficient adsorption of gold ions from aqueous systems with thioamide-group chelating nanofiber membranes. Chem Eng J 2013, 229:420-428.

[102] Ki CS, Gang EH, Um IC and Park YH: Nanofiber membrane of wool keratose/silk fibroin blend for heavy metal ion adsorption. J Membr Sci 2007, 302:20-26.

[103] Haider S, Park SY: Preparation of the electrospun chitosan nanofibers and their applications to the adsorption of $\mathrm{Cu}$ (II) and $\mathrm{Pb}$ (II) ions from an aqueous solution. J Membr Sci 2009, 328:90-96.

[104] Wu SJ, Li FT, Xu R, Wei SH, Wang HT: Preparation of poly (vinyl alcohol)/silica composite nanofibers membrane functionalized with mercapto groups by electrospinning. Mater Lett 2010, 64:1295-1298. 
[105] Li N, Bai R, Liu C: Enhanced and Selective Adsorption of Mercury Ions on Chitosan Beads Grafted with Polyacrylamide via Surface-Initiated Atom Transfer Radical Polymerization. Langmuir 2005, 21:11780-11787.

[106] Choi J, Ide A, Truong YB, Kyratzis IL, Caruso RA: High surface area mesoporous titanium-zirconium oxide nanofibrous web: a heavy metal ion adsorbent. J Mater Chem A 2013, 19:5847-5853.

[107] Wu S, Li F, Wu Y, Xu R, Li G: Preparation of novel poly(vinyl alcohol)/SiO 2 composite nanofiber membranes with mesostructure and their application for removal of $\mathrm{Cu}^{2+}$ from waste water. Chem Commun 2010, 46:1694-1696.

[108] Aliabadi M, Irani M, Ismaeili J, Najafzadeh S: Design and evaluation of chitosan/hydroxyapatite composite nanofiber membrane for the removal of heavy metal ions from aqueous solution. J Taiwan Inst Chem E 2014, 45:518-526.

[109] Wang X, Min M, Liu Z, Yang, Y, Zhou Z, Zhu M, Chen Y, Hsiao BS: Poly(ethyleneimine) nanofibrous affinity membrane fabricated via one step wetelectrospinning from poly(vinyl alcohol)-doped poly(ethyleneimine) solution system and its application. J Membr Sci 2011, 379:191-199.

[109•] Cross-linked electrospun PEI nanofibrous membranes doped with PVA were fabricated by wet-electrospinning in a one-step method instead of the conventional electrospinning and subsequent crosslinking method. This study provides the new route to use PEI for removal of the toxic heavy metal ions from the wastewater.

[110] Kampalanonwat P, Supaphol P: Preparation of hydrolyzed electrospun polyacrylonitrile fiber mats as chelating substrates: A case study on copper (II) ions. Ind Eng Chem Res 2011, 50:11912-11921.

[111] Han D, Halada GP, Spalding B, Brooks SC: In: Model Cellulosic Surfaces. Roman, M, Ed; American Chemical Society: Washington, DC, 2010: 243-257. 
[112] Feng Q, Wang X, Wei A, Wei Q, Hou D, Luo W, Liu X, Wang Z: Surface modified polyacrylonitrile nanofibers and application for metal ions chelation. Fiber Polym 2011, 12:1025-1029.

[113] Saeed K, Park SY, Oh TJ: Preparation of hydrazine-modified polyacrylonitrile nanofibers for the extraction of metal ions from aqueous media. J Appl Polym Sci 2011, 121:869873.

[114] Deng S, Bai R, Chen JP: Aminated polyacrylonitrile fibers for lead and copper removal. Langmuir 2003, 19:5058-5064.

[115 ${ }^{\circ}$ Taha AA, Qiao J, Li F, Zhang B: Preparation and application of amino functionalized mesoporous nanofiber membrane via electrospinning for adsorption of $\mathrm{Cr}^{3+}$ from aqueous solution. J Environ Sci 2012, 24:610-616.

[115 ${ }^{\circ}$ Mesoporous amino functionalized nanofiber affinity membrane provided not only abundant amino groups but also large effective surface area, resulting in very high adsorption capacity toward $\mathrm{Cr}^{3+}$ ions.

[116] Wu J, Wang N, Wang L, Dong H, Zhao Y, Jiang L: (2012) Electrospun Porous Structure Fibrous Film with High Oil Adsorption Capacity. ACS Appl Mater Interfaces 4:32073212.

[117] Lin JY, Shang YW, Ding B, Yang JM, Yu JY, Al-Deyab SS: Nanoporous polystyrene fibers for oil spill cleanup. Mar Pollut Bull 2012, 64:347-352.

[118] Lin JY, Ding B, Yang JM, Yu JY, Sun G: Subtle regulation of the micro- and nanostructures of electrospun polystyrene fibers and their application in oil absorption. Nanoscale $2012,4: 176-182$.

[119] Lin JY, Tian F, Shang YW, Wang FJ, Ding B, Yu JY: Facile control of intra-fiber porosity and inter-fiber voids in electrospun fibers for selective adsorption. Nanoscale 2012, 4:5316-5320. 
[120] Zhu HT, Qiu SS, Jiang W, Wu DX, Zhang CY: Evaluation of Electrospun Polyvinyl Chloride/Polystyrene Fibers As Sorbent Materials for Oil Spill Cleanup. Environ Sci Technol 2011, 45:4527-4531.

[121] Lin JY, Tian F, Shang YW, Wang FJ, Ding B, Yu JY, Guo Z : Co-axial electrospun polystyrene/polyurethane fibres for oil collection from water surface. Nanoscale 2013, 5:27452755.

[122] Liu H, Cao CY, Wei FF, Huang PP, Sun YB, Jiang L, Song WG: Flexible macroporous carbon nanofiber film with high oil adsorption capacity. J Mater Chem A 2014, 2:3557-3562.

[123] Si Y, Ren T, Ding B, Yu J, Sun G: Synthesis of mesoporous magnetic $\mathrm{Fe}_{3} \mathbf{O}_{4} @$ carbon nanofibers utilizing in situ polymerized polybenzoxazine for water purification. $J$ Mater Chem 2012, 22:4619-4622.

[124] Si Y, Ren T, Li Y, Ding B, Yu J: Fabrication of magnetic polybenzoxazine-based carbon nanofibers with $\mathrm{Fe}_{3} \mathrm{O}_{4}$ inclusions with a hierarchical porous structure for water treatment. Carbon 2012, 50:5176-5185.

[125] Ren T, Si Y, Yang J, Ding B, Yang X, Hong F, Yu J: Polyacrylonitrile/polybenzoxazinebased $\mathrm{Fe}_{3} \mathrm{O}_{4} @$ carbon nanofibers: hierarchical porous structure and magnetic adsorption property. J Mater Chem 2012, 22:15919-15927.

[126] Miao Y-E, Wang R, Chen D, Liu Z, Liu T: Electrospun self-standing membrane of hierarchical $\mathrm{SiO}_{2} @ \gamma$-AIOOH (Boehmite) core/sheath fibers for water remediation. ACS Appl Mater Interfaces 2012, 4:5353-5359.

[127] Li M, Wang H, Wu S, Li F, Zhi P: Adsorption of hazardous dyes indigo carmine and acid red on nanofiber membranes. RSC Adv 2012, 2:900-907.

[128] Teng M, Qiao J, Li F, Bera PK: Electrospun mesoporous carbon nanofibers produced from phenolic resin and their use in the adsorption of large dye molecules. Carbon 2012, 50:2877-2886. 
[129] Ma Z, Kotaki M, Ramakrishna S: Surface modified nonwoven polysulphone (PSU) fiber mesh by electrospinning: A novel affinity membrane. J Membr Sci 2006, 272:179-187.

[130] Ma Z, Kotaki M, Ramakrishna S: Electrospun cellulose nanofiber as affinity membrane. J Membr Sci 2005, 265:115-123.

[131] Schneidermana S, Zhang L, Fong H, Menkhausa TJ: Surface-functionalized electrospun carbon nanofiber mats as an innovative type of protein adsorption/purification medium with high capacity and high throughput. J Chromatogr A 2011, 1218:8989-8995.

[132] Yue X, Feng S, Li S, Jing Y, Shao C: Bromopropyl functionalized silica nanofibers for effective removal of trace level dieldrin from water. Colloids Surf A 2012, 406:44-51.

[133] Chakrabarty T, Kumar M, Rajesh KP, Shahi VK, Natarajan TS: Nanofibrous sulfonated poly (ether ether ketone) membrane for selective electro-transport of ions. Sep Purif Technol 2010, 75:174-182.

$\left[133^{\circ}\right]$ Electrospun sulfonated poly(etheretherketone) nanofiber membrane was found to exhibit very low flux and electro-transport efficiency for bi-valent cations, which made it a promising candidate for purifying brackish water into potable drinking water from and for application in the chlor-alkali industry.

[134] Pan J, Ge L, Lin X, Wu L, Wu B, Xu T: Cation exchange membranes from hot-pressed electrospun sulfonated poly(phenyleneoxide) nanofibers for alkali recovery. $\mathrm{J}$ Membr Sci 2014, 470:479-485.

[135] Choi J, Lee KM, Wycisk R, Pintauro PN, Mather PT: Nanofiber network ion-exchange membranes. Macromolecules 2008, 41:4569-4572.

[136 ${ }^{\circ}$ Park AM, Turley FE, Wycisk RJ, Pintauro PN: Electrospun and Cross-Linked Nanofiber Composite Anion Exchange Membranes. Macromolecules 2014, 47:227-235.

[136 $\left.{ }^{\circ}\right]$ The authors fabricated a family of highly conductive and mechanically robust anion exchange membranes with unique cross-linked nanofiber composite morphology for alkaline fuel cell applications. 
[137] Wang L, Dou L, Zhang S: Nanofiber-based poly(aryl ether sulfone) containing guanidinium groups as novel anion-exchange membranes. J Polym Res 2013, 20:232-237. 


\section{Figure Captions}

Figure 1. An overview of the potential applications for polymer nanofibers.

Figure 2.Schematic illustration of the electrospinning process. [2]

Figure3. SEM images of (A) electrospun PVDF nanofiber membrane after filtration with $10 \mu \mathrm{m}$ PS particles and reverse washing, (B) electrospun PSF membrane after $1.0 \mu \mathrm{m}$ particle separation, and (C) after $0.1 \mu \mathrm{m}$ particle separation at about $1 \mu \mathrm{m}$ below the membrane surface. [37,38]

Figure 4. SEM images of electrospun PAN/PET membrane after E. coli suspension filtration, from (A) surface and (B) cross-section views. [44]

Figure 5. (a) Illustration of the synthesis of hierarchical porous silica nanofibrous (SNF) membranes by combining the nanofibers with in situ polymerization. (b) Photograph of oil and water on the SNF-0 membranes in air, and an underwater oil droplet on the SNF-0 membranes. (c) Photographs showed the facile gravity-driven separation of oil-in-water micro-emulsions using SNF-2 membranes. [58 $\left.{ }^{\circ}\right]$

Figure 6.Schematic diagram of the three-layered TFNC membrane system (left) and representative SEM image of electrospun PVA substrate (right). [77]

Figure 7. (Left) Schematic hierarchical structure of TFNC membrane containing three layers of randomly deposited fibers with different diameters. (Right) Cross-sectional

SEM views of the barrier layer and electrospun nanofibrous scaffold in a typical TFNC membrane. [78*0]

Figure 8. Schematic illustration of the fabrication process for TFNC membranes based on PAN nanofibrous substrate and cross-linked PVA barrier layer. [86

Figure 9. TEM cross-section images of (A) IP based membrane, (B) IP-R based membrane on the $\mathrm{CN}$ (cellulose nanofibers)/PAN (electrospun nanofibers)/PET (non-woven substrate) composite scaffold, where their corresponding schematics are shown in (C) and (D), respectively. [94]

Figure 10. Adsorption mechanism of (a) heavy metal ions and (b) anionic dyes onto the "macro-nano" structure of PEI/PES nanofibrous affinity membranes. [99"]

Figure 11.(A) Schematic diagram illustrating the formation process of porous 
nanofibers during electrospinning. SEM images of the PS $\left(\mathrm{M}_{\mathrm{w}}=208,000 \mathrm{~g} / \mathrm{mol}\right)$ fibers formed from (B) $10 \mathrm{wt} \%$ and (C) $30 \mathrm{wt} \%$ PS in THF-DMF with a weight ratio of 20:80. (D) Maximum absorption capacities of porous PS fibrous mats and commercial PP nonwoven fibers for motor oil and sunflower seed oil. [118]

Figure 12. Schematic illustration of the preparation of $\mathrm{SiO}_{2} @ \gamma-\mathrm{AlOOH}$ (Boehmite) core/sheath fibers, and Congo red solution before and after adsorption by this core/sheath fiber membrane. [126] 


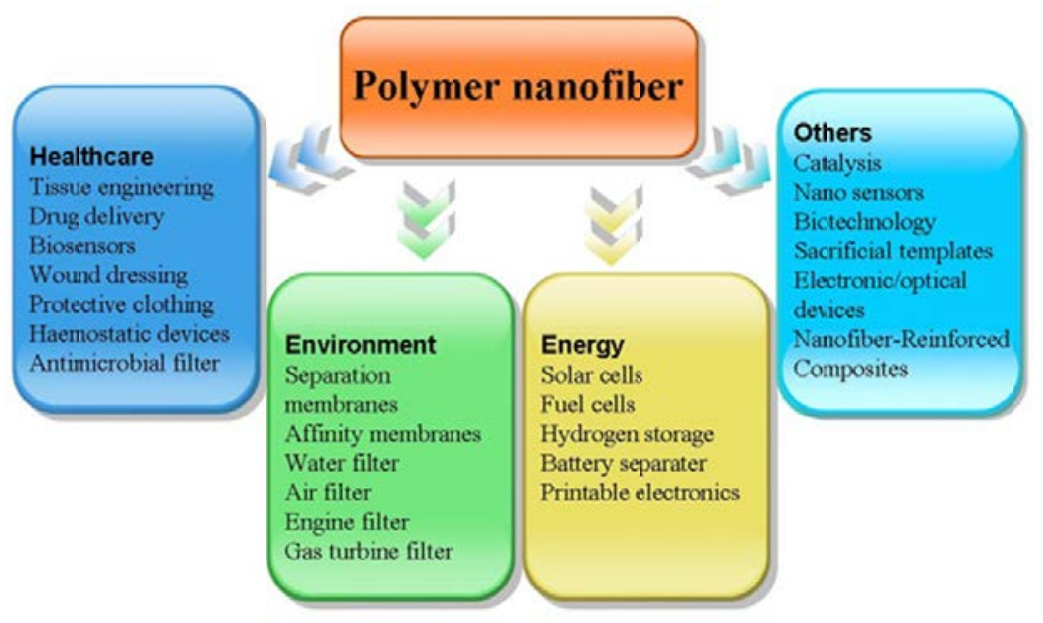

Figure1. An overview of the potential applications for polymer nanofibers. 


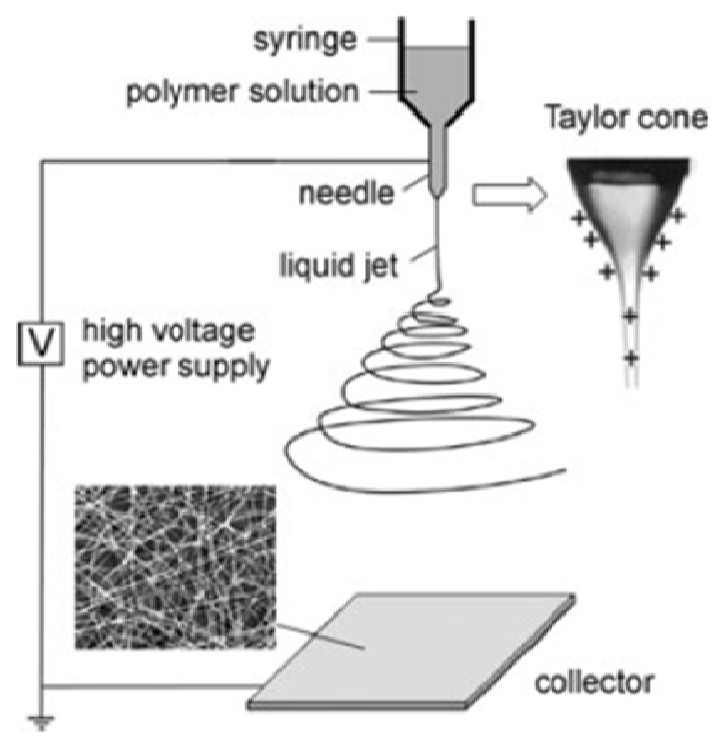

Figure2.Schematic illustration of the electrospinning process. [2] 

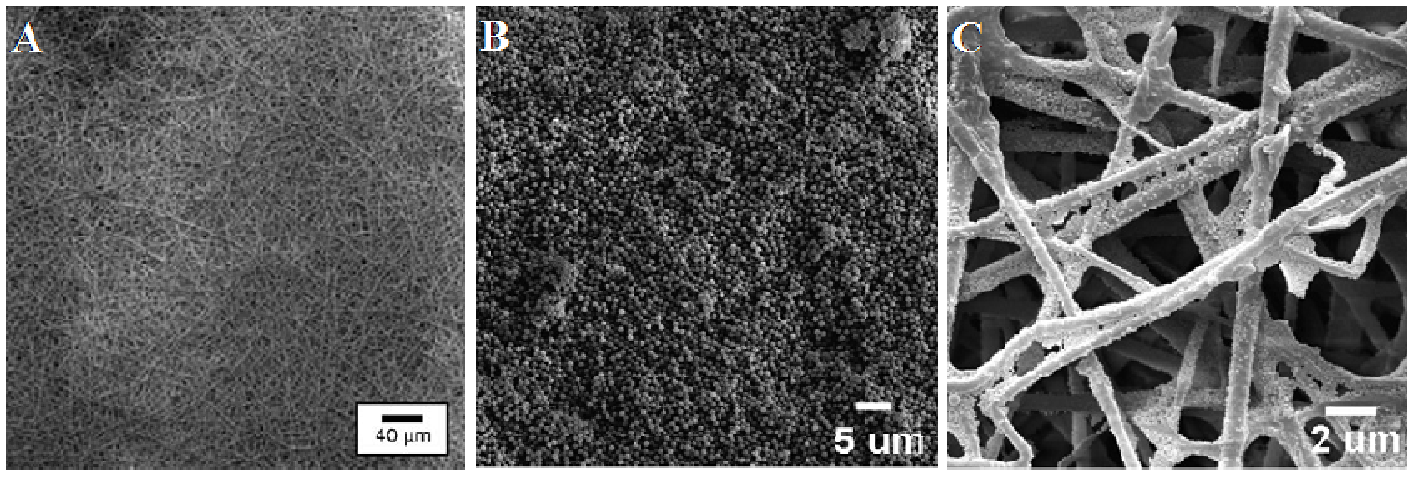

Figure3. SEM images of (A) electrospun PVDF nanofiber membrane after filtration with $10 \mu \mathrm{m}$ PS particles and reverse washing, (B) electrospun PSF membrane after $1.0 \mu \mathrm{m}$ particle separation, and (C) after $0.1 \mu \mathrm{m}$ particle separation at about $1 \mu \mathrm{m}$ below the membrane surface. $[37,38]$ 


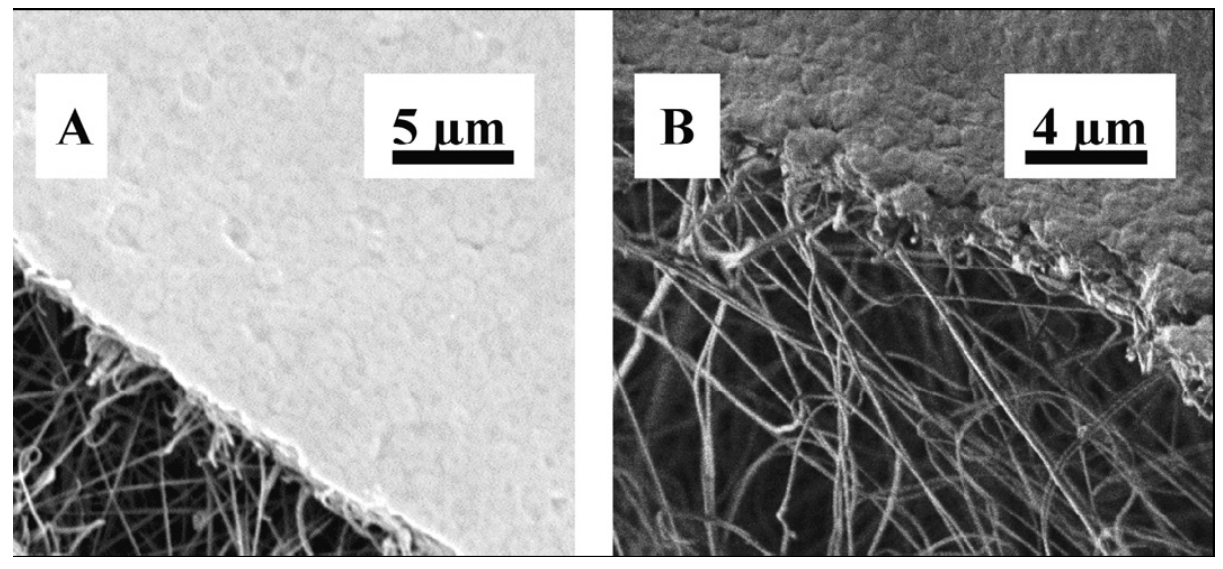

Figure4. SEM images of electrospun PAN/PET membrane after E. coli suspension filtration, from (A) surface and (B) cross-section views. [44] 


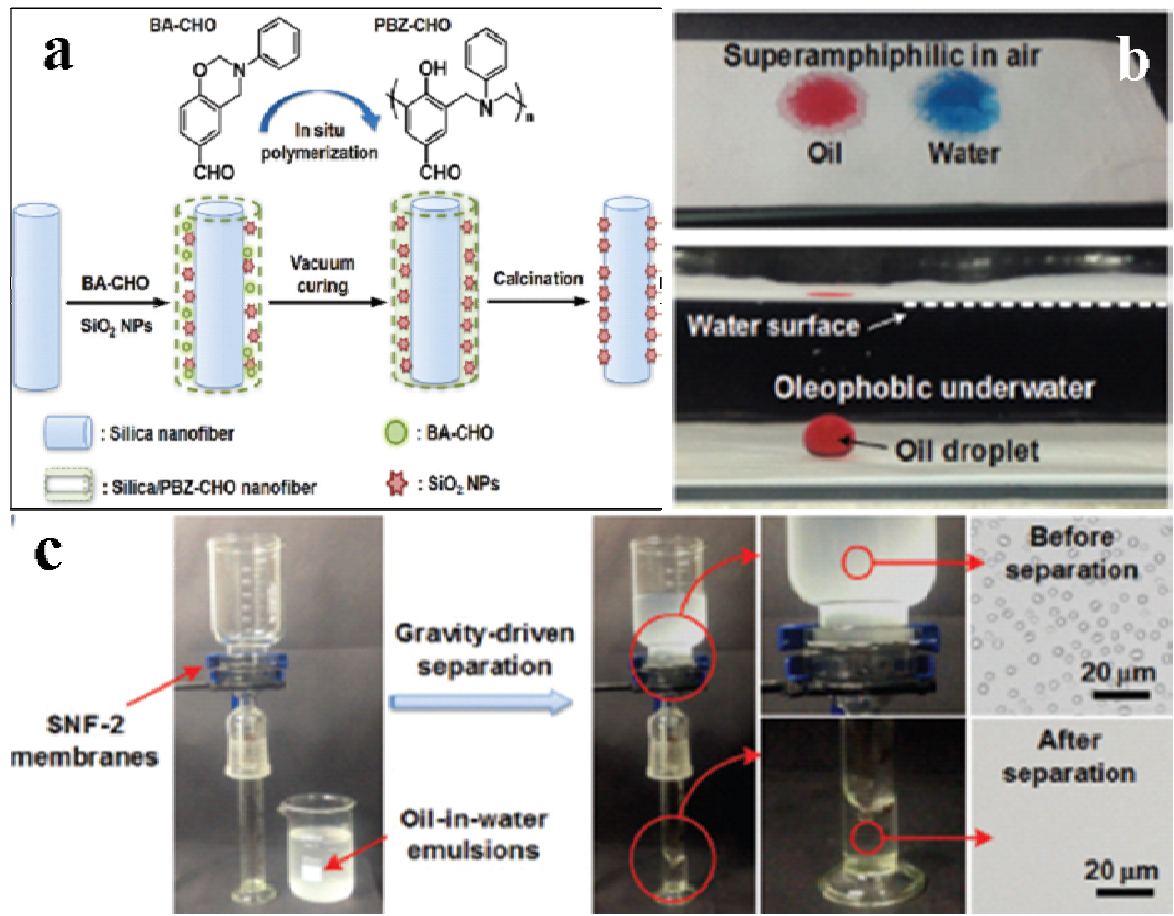

Figure5. (a) Illustration of the synthesis of hierarchical porous silica nanofibrous (SNF) membranes by combining the nanofibers with in situ polymerization. (b) Photograph of oil and water on the SNF-0 membranes in air, and an underwater oil droplet on the SNF-0 membranes. (c) Photographs showed the facile gravity-driven separation of oil-in-water micro-emulsions using SNF-2 membranes. [58 $\left.{ }^{\circ}\right]$ 


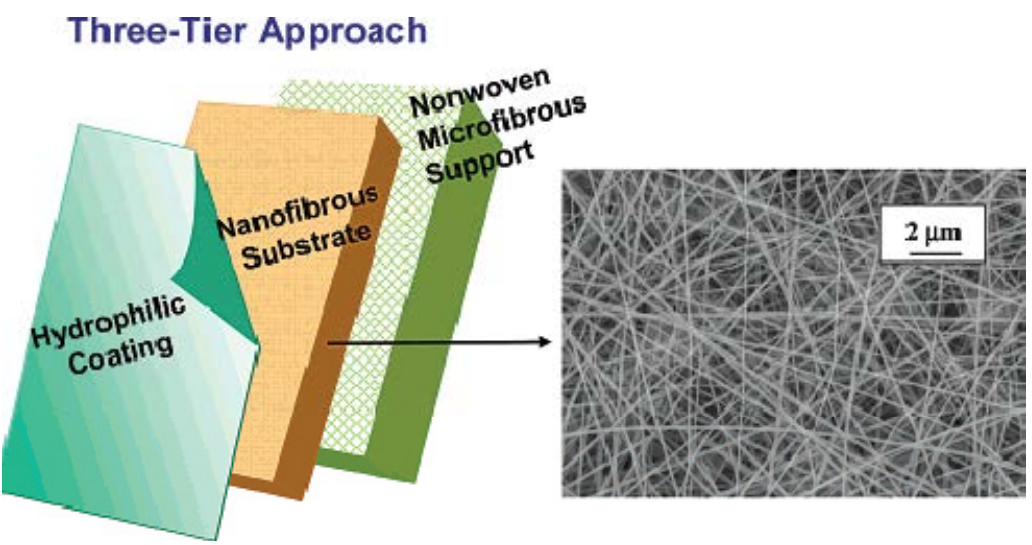

Figure6.Schematic diagram of the three-layered TFNC membrane system (left) and representative SEM image of electrospun PVA substrate (right). [77] 


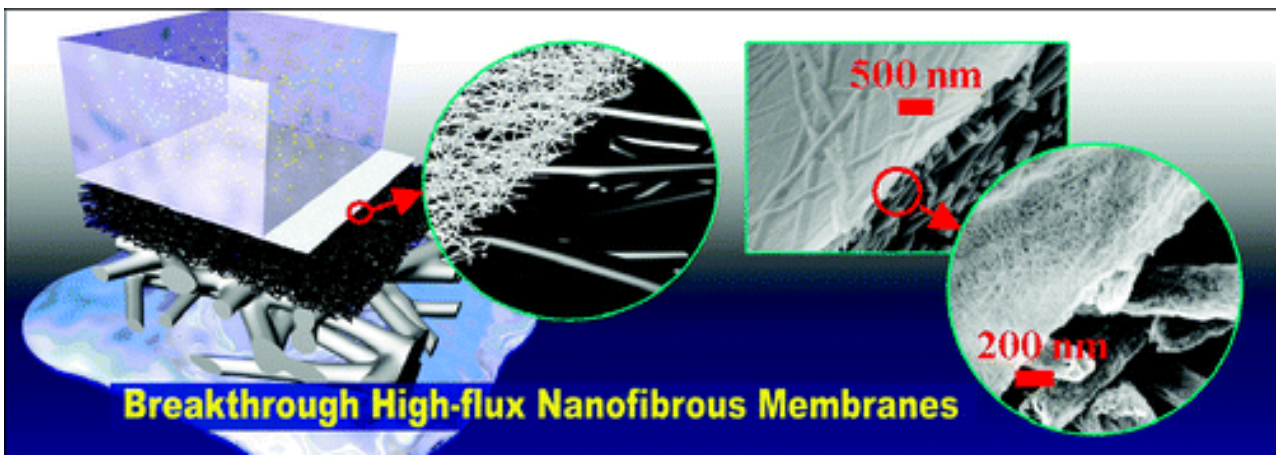

Figure7. (Left) Schematic hierarchical structure of TFNC membrane containing three layers of randomly deposited fibers with di $\square$ erent diameters. (Right) Cross-sectional SEM views of the barrier layer and electrospun nanofibrous sca $\square$ old in a typical TFNC membrane. [78*0] 


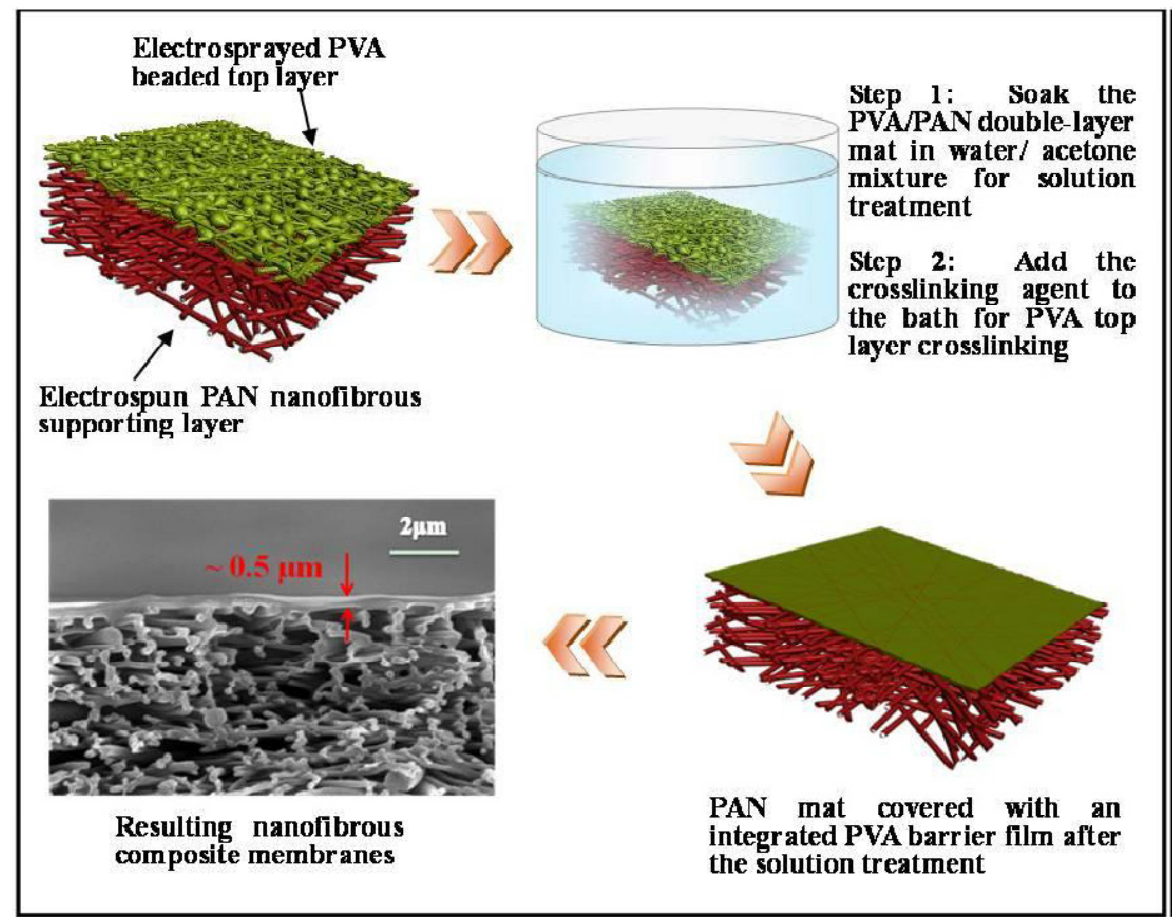

Figure8. Schematic illustration of the fabrication process for TFNC membranes based on PAN nanofibrous substrate and cross-linked PVA barrier layer. [86 ${ }^{\circ}$ 

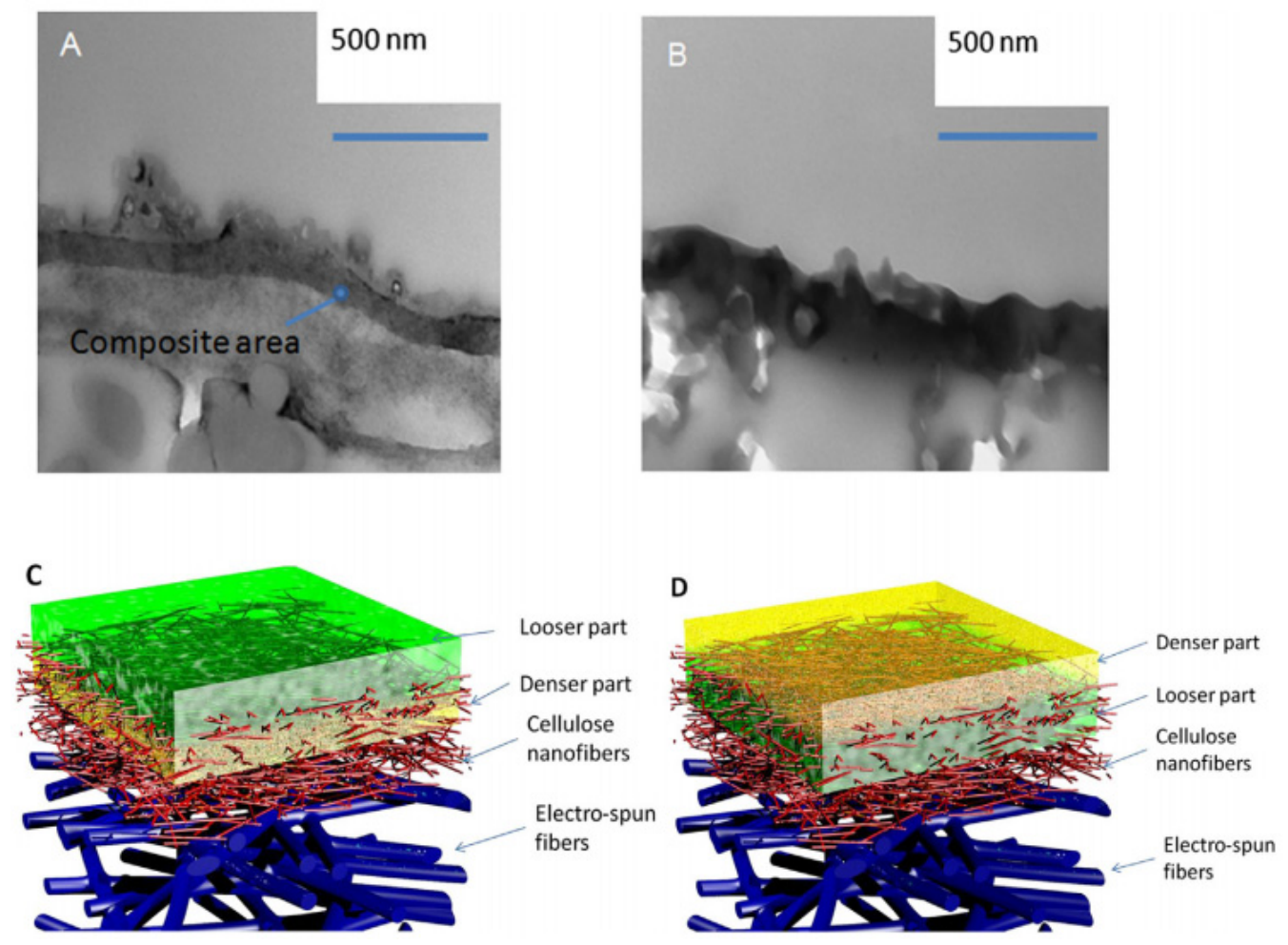

Figure9. TEM cross-section images of (A) IP based membrane, (B) IP-R based membrane on the $\mathrm{CN}$ (cellulose nanofibers)/PAN (electrospun nanofibers)/PET (non-woven substrate) composite scaffold, where their corresponding schematics are shown in (C) and (D), respectively. [94] 


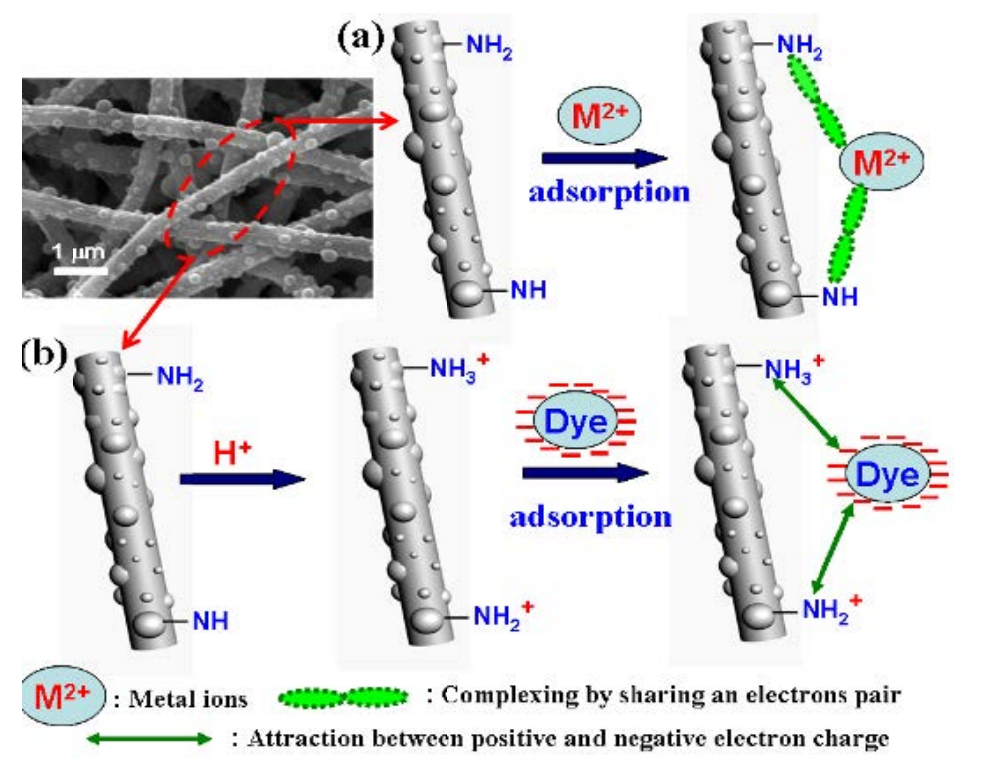

Figure 10. Adsorption mechanism of (a) heavy metal ions and (b) anionic dyes onto the "macro-nano" structure of PEI/PES nanofibrous affinity membranes. [99*0] 


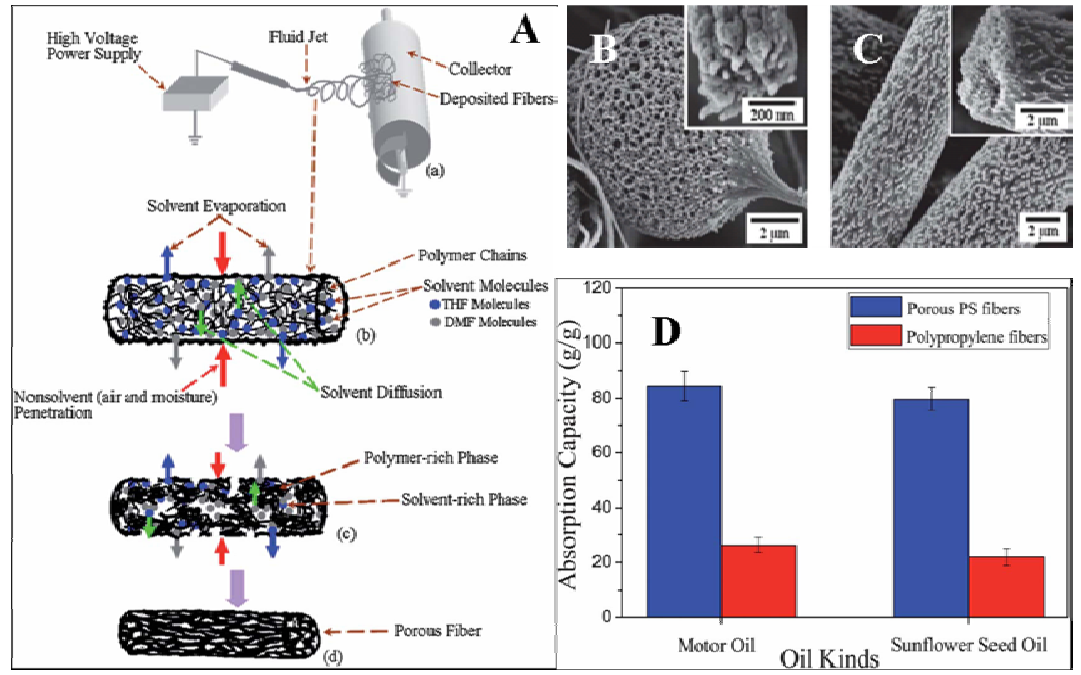

Figure 11.(A) Schematic diagram illustrating the formation process of porous nanofibers during electrospinning. SEM images of the PS $\left(M_{w}=208,000 \mathrm{~g} / \mathrm{mol}\right)$ fibers formed from (B) $10 \mathrm{wt} \%$ and (C) $30 \mathrm{wt} \%$ PS in THF-DMF with a weight ratio of 20:80. (D) Maximum absorption capacities of porous PS fibrous mats and commercial PP nonwoven fibers for motor oil and sunflower seed oil. [118] 


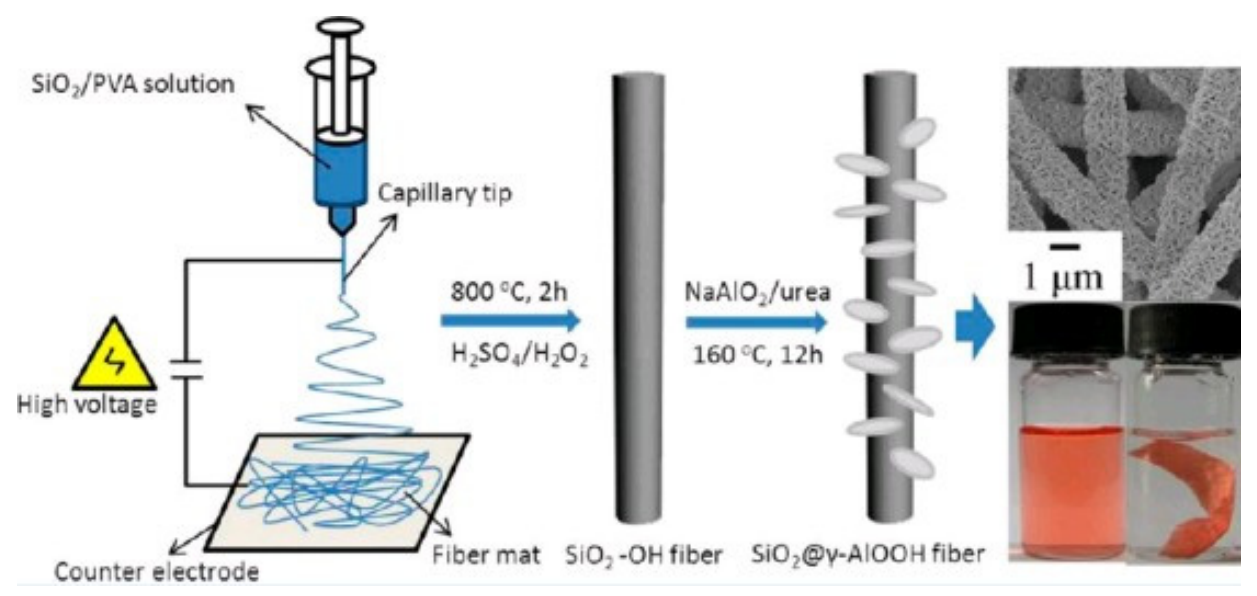

Figure 12. Schematic illustration of the preparation of $\mathrm{SiO}_{2} @ \gamma-\mathrm{AlOOH}$ (Boehmite) core/sheath fibers, and Congo red solution before and after adsorption by this core/sheath fiber membrane. [126] 